\title{
Hyaluronan synthase 3 mediated oncogenic action through forming inter-regulation loop with tumor necrosis factor alpha in oral cancer
}

\author{
Yi-Zih Kuo ${ }^{1}$, Wei-Yu Fang1, Cheng-Chih Huang ${ }^{2}$, Sen-Tien Tsai ${ }^{2,3}$, Yi-Ching Wang ${ }^{4}$, \\ Chih-Li Yang ${ }^{5}$, Li-Wha Wu ${ }^{1,5,6}$ \\ ${ }^{1}$ Institute of Basic Medical Sciences, College of Medicine, National Cheng Kung University, Tainan 70101, Taiwan, R.0.C \\ ${ }^{2}$ Department of Otolaryngology, National Cheng Kung University Hospital, Tainan 70428, Taiwan, R.O.C \\ ${ }^{3}$ Department of Radiation Oncology, National Cheng Kung University Hospital, Tainan 70428, Taiwan, R.O.C \\ ${ }^{4}$ Department of Pharmacology, College of Medicine, National Cheng Kung University, Tainan 70101, Taiwan, R.O.C \\ ${ }^{5}$ Institute of Molecular Medicine, College of Medicine, National Cheng Kung University, Tainan 70101, Taiwan, R.O.C \\ ${ }^{6}$ Department of Medical Laboratory Science and Biotechnology, Kaohsiung Medical University, Kaohsiung 80708, Taiwan, \\ R.O.C. \\ Correspondence to: Li-Wha Wu, email: liwhawu@mail.ncku.edu.tw \\ Sen-Tien Tsai, email: T602511@mail.ncku.edu.tw
}

Keywords: hyaluronan, HAS3, oral cancer, TNF-a, MCP-1

Received: July 20, 2016

Accepted: December 27, 2016

Published: January 17, 2017

\section{ABSTRACT}

Hyaluronan (HA) is a major extracellular matrix component. However, its role and mediation in oral cancer remains elusive. Hyaluronan synthase 3 (HAS3), involved in pro-inflammatory short chain HA synthesis, was the predominant synthase in oral cancer cells and tissues. HAS3 overexpression significantly increased oral cancer cell migration, invasion and xenograft tumorigenesis accompanied with the increased expression of tumor necrosis factor alpha (TNF-a) and monocyte chemoattractant protein 1 (MCP-1). Conversely, HAS3 depletion abrogated HAS3-mediated stimulation. HAS3 induced oncogenic actions partly through activating EGFR-SRC signaling. HAS3derived HA release into extracellular milieu enhanced transendothelial monocyte migration and MCP-1 expression, which was attenuated by anti-HAS3 antibodies or a HAS inhibitor, 4-Methylumbelliferone (4-MU). The NF-KB-binding site III at $\mathbf{- 1 6 9 2}$ to $\mathbf{- 1 6 8 2}$ bp upstream from the transcript 1 start site in HAS3 proximal promoter was the most responsive to TNF-a-stimulated transcription. ChIP-qPCR analysis confirmed the highest NF-KB-p65 enrichment on site III. Increased HAS3 mRNA expression was negatively correlated with the overall survival of oral cancer patients. A concomitant increase of TNF-a, a stimulus for HAS3 expression, with HAS3 expression was not only associated with lymph node metastasis but also negated clinical outcome. Together, HAS3 and TNF-a formed an inter-regulation loop to enhance tumorigenesis in oral cancer.

\section{INTRODUCTION}

Hyaluronan (HA), a polysaccharide of repeating units of D-glucuronic acid and N-acetyl-glucosamine in body fluids and tissues, is an essential component of extracellular matrix [1]. HA regulates target cell adhesion, migration and proliferation, and participates in tissue homeostasis and biomechanical integrity $[2,3]$. In addition to regulating inflammatory gene expression, immune cell recruitment, and cytokine release [4], HA also promotes tumor angiogenesis [5]. HA is overproduced by many cancer types and, in some cases, the level of HA is prognostic for malignant progression $[1,6]$. Increased HA levels may thus provide an environment facilitating various aspects of tumor progression.

HA synthases (HASs) are unique plasma membrane glycosyltransferases. Three related synthases, HAS1, HAS2 and HAS3, synthesize and secrete different sizes of HA polmers directly to the extracellular space in human cells [7, 8]. High-molecular-mass HA (HMM-HA) 
represses mitogenic signaling with anti-inflammatory properties, whereas low-molecular-mass HA (LMMHA) promotes proliferation and inflammation [9, 10]. HAS1 with the lowest enzymatic activity maintains a low basal HA level. Although HAS2 is the most studied synthase involved in embryonic and cardiac cushion morphogenesis and can stimulate cell proliferation and angiogenesis, HAS3 is the most active in the synthesis of short chain HA (100 1000 kDa) and highly expressed in tumor cells [7]. Elevated HAS3 expression promoted the growth of prostate, colon and pancreatic cancer cells and angiogenesis in prostate cancer [11-13]. Systemic inhibition of HA synthesis or HAS3 knockdown decreased esophageal xenograft tumorigenesis [14]. In contrast to a potential oncogenic role of HAS enzymes in carcinogenesis, HAS3 under-expression was a poor prognositic marker for bladder cancer [15] and the promoter methylation of HAS3 was recently proposed to regulate hyaluronan production in pancreatic cancer [16].

HA has been associated with tumorigenesis for some time [17]. Overall, about $25-30 \%$ of human tumors overexpress HA [18]. HA was also increasingly released in oral cancer patient sera relative to those in patients with benign tumors and in healthy controls [19]. By constrast, the reduction of HA staining was correlated with poor survival in oral cancer patients [20]. HA synthesis is one important mechanism for HA accumulation in tumors [21]. The exact role of HA and the contribution of individual HAS enzymes in oral cancer, therefore, remains to be characterized. The present study was aimed to study the role of the over-represented HAS member by overexpression or knockdown approaches in oral cancer and examine the action mechanism of the HAS-derived HA involved in the crosstalk between oral cancer cells and their microenvironment. Our data support an important role of HAS3-mediated short-chain HA for providing a favorable environment for oral carcinogenesis.

\section{RESULTS}

\section{Predominant HAS3 expression in most oral cancer cells}

With frequently altered HAS expression in several cancer types [22], we studied if HAS enzymes were also deregulated in oral cancer. Due to $57-71 \%$ amino acid identity among HAS members [23] and possible contribution of HAS expression from different cell types [24] in clinical specimens, we measured relative HAS1-3 mRNA expression in 6 oral cancer lines by using qRTPCR. HAS3 mRNA was most expressed in 5 oral cancer lines (Figure 1A). We further compared the expression in oral cancer cells with normal counterparts, NOK or DOK. Oral cancer cells manifested an increase of HAS3 mRNA and protein expression in most oral cancer lines relative to normal counterparts (Figure 1B-1C). Together, HAS3 was the dominantly expressed HA synthase in most oral cancer cell lines.

\section{Increased HAS3 expression mainly promoted oral cancer migration and invasion}

To study the role of HAS3 dergulation in oral cancer, we manipulated HAS3 expression in oral cancer lines, OC-2 and OC-3, followed by using various cellbased transformation assays. We confirmed ectopic Myctagged HAS3 as well as total HAS3 protein in these cells by Western blot analysis and the consequent increase of HA accumulation in the CM by ELISA (Figure 2A and 2B). We next examined whether altered HAS3 expression would affect oral cancer cell growth, migration, and invasion. Ectopic HAS3 expression increased OC-2 but not OC-3 proliferation (Figure 2C). In Transwell migration and invasion assays, increased HAS3 expression promoted the migration and invasion of both OC-2 and OC-3 cells (Figure 2D).

To validate oncogenic promotion exerted by ectopic HAS3 expression, we depleted HAS3 expression in OC-2 expressing Myc-HAS3 cells by transduction with lentiviruses bearing control shLuc or shHAS3 clones (\#1 or \#2). Western blot and ELISA analyses confirmed the concordant decrease of HAS3 protein expression and HA production in HAS3-depleted cells (Figure 3A-3B). The knockdown reduced not only the proliferation but also the migration and matrigel invasion of OC2 cells (Figure 3C-3D). Endogenous HAS3 silencing also recapitulated the findings of knocking down ectopic HAS3 in oral cancer cells (Supplementary Figure 1). Together, enhanced HAS3 expression primarily promoted oral cancer cell migration and invasion while having cell-type specific effect on cell proliferation.

\section{Ectopic HAS3 expression promoted xenograft tumorigenesis}

To investigate the effect of HAS3 overexpression on xenograft tumorigenesis, we subcutaneously injected vector- or HAS3-expressing OC-2 cells onto male nude mice (10 mice/group) for 32 days. Ectopic HAS3 promoted OC-2 tumor volume and weights compared to vector control (Figure 4A-4B). IHC staining showed a significant increase of proliferating Ki67-positive cells and CD31-positive microvessel numbers in HAS3 tumors relative to vector tumors (Figure 4C). Ectopic HAS3 expression significantly promoted xenograft tumorigenesis.

\section{Oncogenic HAS3 activated SRC-EGFR signaling axis in oral cancer cells}

Increased HAS3 expression promoted HA production in the $\mathrm{CM}$ (Figure $2 \mathrm{~B}$ ). HA binding promotes 


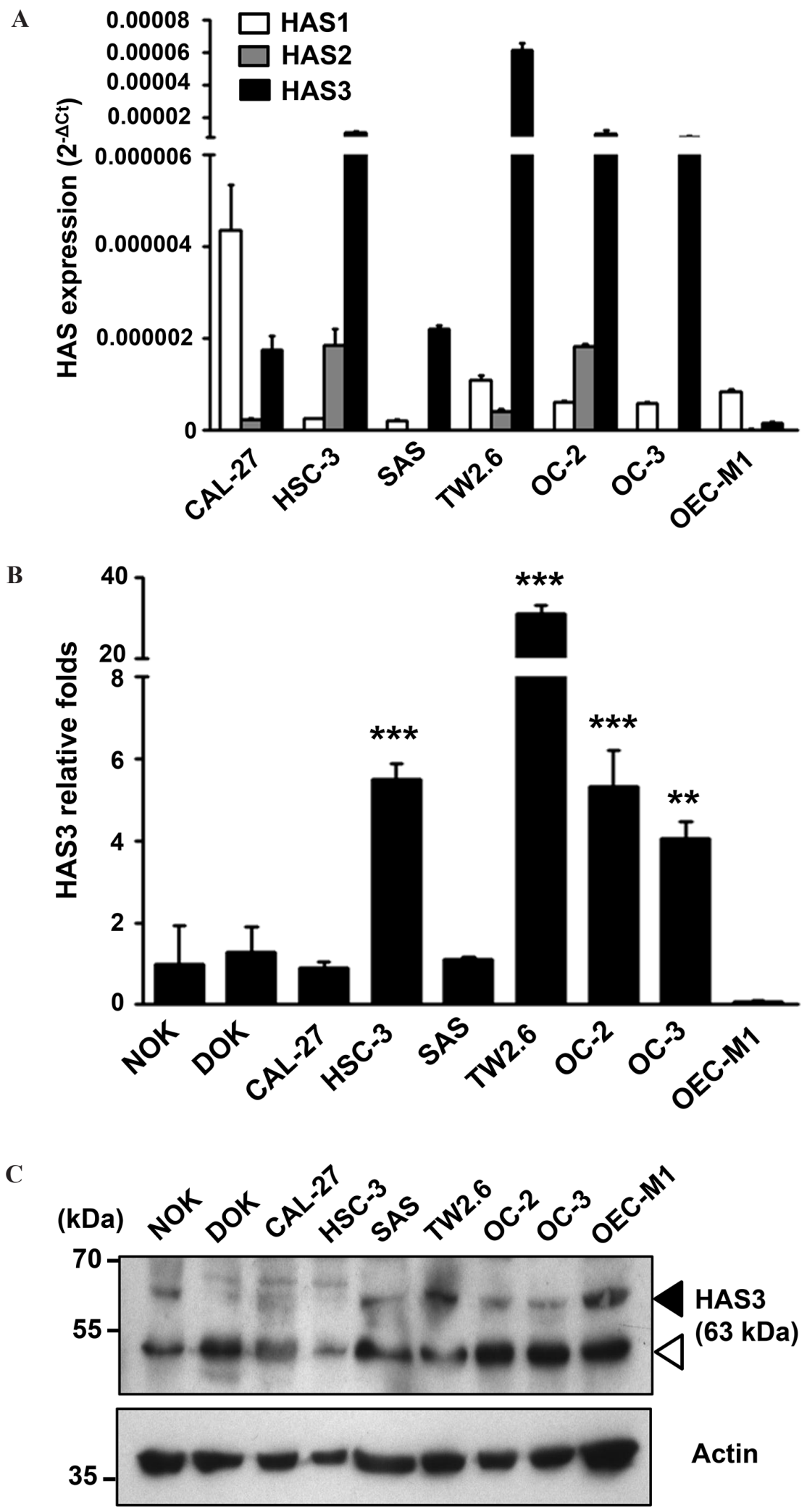

Figure 1: Predominant HAS3 expression in oral cancer cells. A. The mRNA expression of HAS1, HAS2 and HAS3 in 6 oral cancer cell lines was measured by qRT-PCR and expressed as $2^{-\Delta C t}$. B. The relative expression of HAS3 mRNA in each oral cell line was measured by qRT-PCR and expressed as relative fold change $\left(2^{-\Delta \Delta \mathrm{Ct}}\right)$ when compared with that in NOK. $* * \mathrm{p}<0.01$ or $* * * \mathrm{p}<0.01$ versus NOK. C. HAS3 protein was measured by Western blot analysis. Actin was a loading control. Black arrowhead, HAS3 protein; white arrowhead, nonspecific band. Results are representative of three independent experiments. ${ }^{* *} \mathrm{p}<0.01$; $* * *$ p $<0.001$ versus NOK; One-way ANOVA and Tukey's multiple comparison test, mean \pm SD. 
A

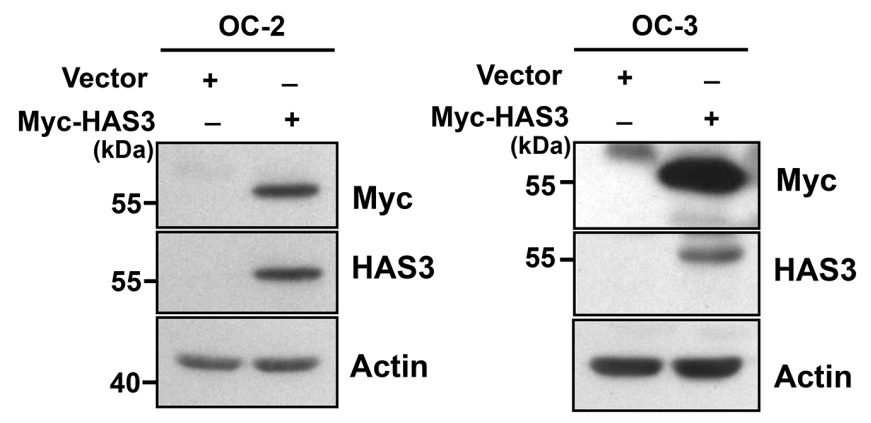

B

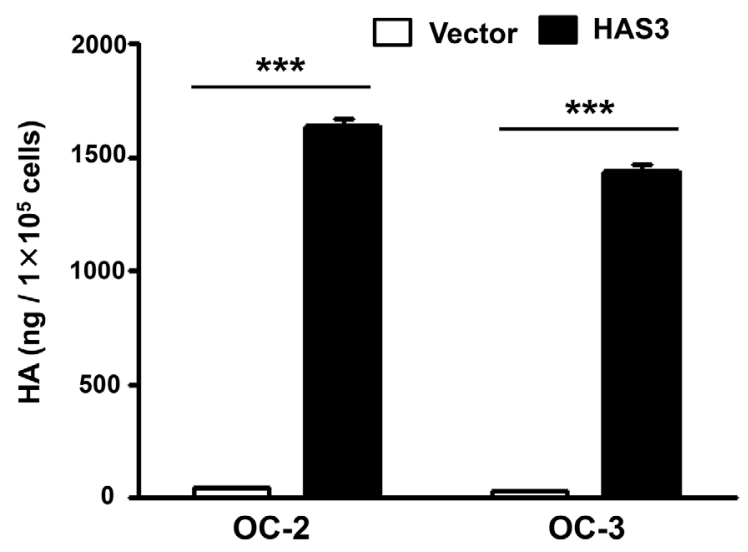

C


D
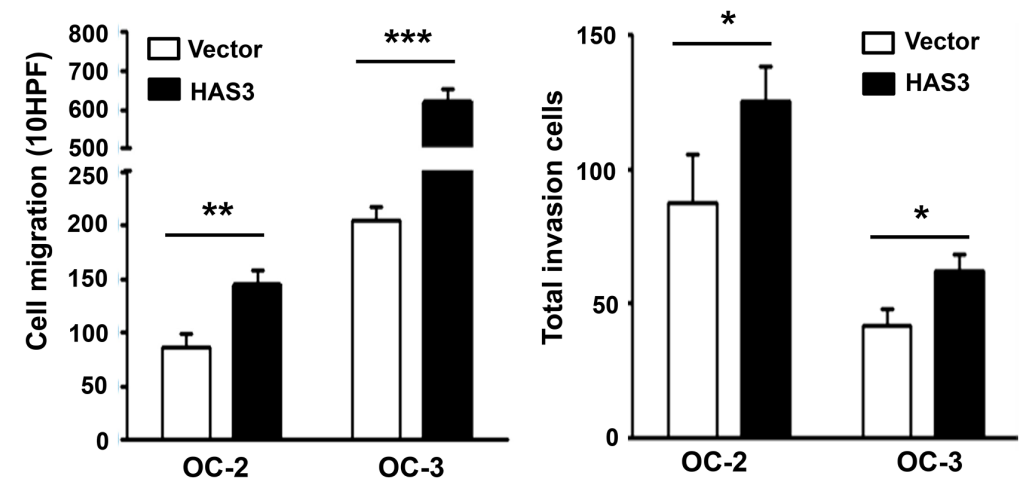

Figure 2: Ectopic HAS3 expression promoted HA accumulation, cell migration, and invasion. A. Oral cancer cells, OC-2 (Left) or OC-3 (Right) were infected with lentiviruses bearing empty vector or Myc-tagged HAS3. Total cell lysates were harvested for Western Blot analysis of ectopic and endogenous HAS3 proteins. The blot shown is representative of three independent experiments. Actin was a loading control. B. HA concentrations in CM derived from the indicated cells were measured by ELISA and expressed as ng per $10^{5}$ cells. C. Viable cell numbers were enumerated by cell proliferation assay. D. Cell migration and invasion abilities were measured, respectively, by Transwell migration (Left) and invasion (Right) assays. C and D results are representative of two-three independent experiments performed in triplicate. ${ }^{*} \mathrm{p}<0.05 ;{ }^{* *} \mathrm{p}<0.01 ; * * * \mathrm{p}<0.001$; N.S, not significant; Student's $t$ test. 
the activating phosphorylation of c-SRC at tyrosine 419 (Y419) in certain epithelial tumor cells [25]. HA also promotes EGFR-mediated signaling [26] and SRC participates in Y845 phosphorylation of EGFR [27]. To investigate the mechanism for HAS3-mediated oncogenic actions, we used Western blot analysis to examine the impact of HAS3 overexpression on the expression of
SRC and EGFR as well as their tyrosine phosphorylation, SRC-Y419 and EGFR-Y845, in OC-2 cells. The increase of HAS3 expression enhanced the levels of SRC-p-Y419 and EGFR-p-Y845 in these cells without affecting the total expression of each protein (Figure 5A). AZD0530 (2 $\mu \mathrm{M})$, an SRC family inhibitor, attenuated HAS3-mediated increase of SRC-p-Y419 in both vector- and HAS3-
A

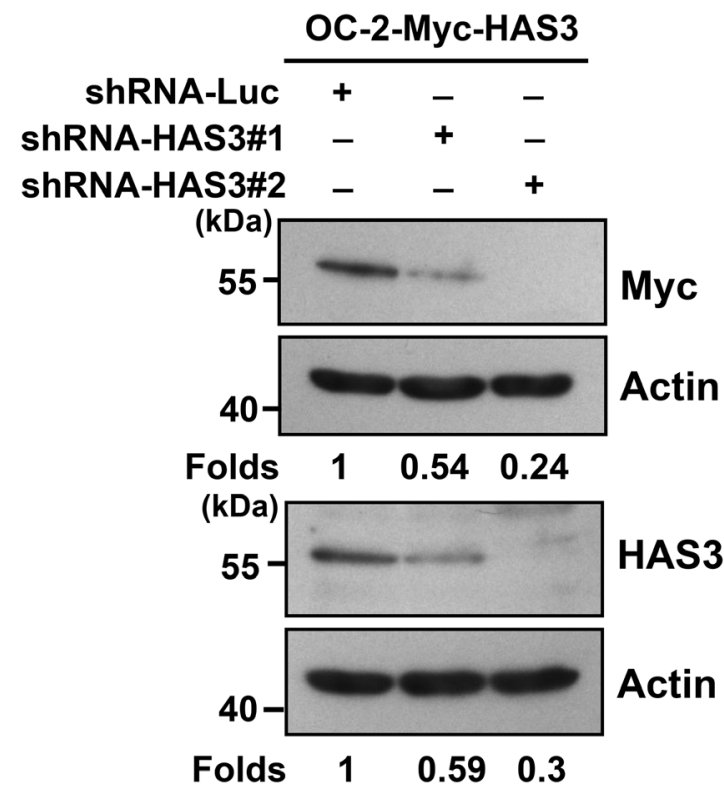

B

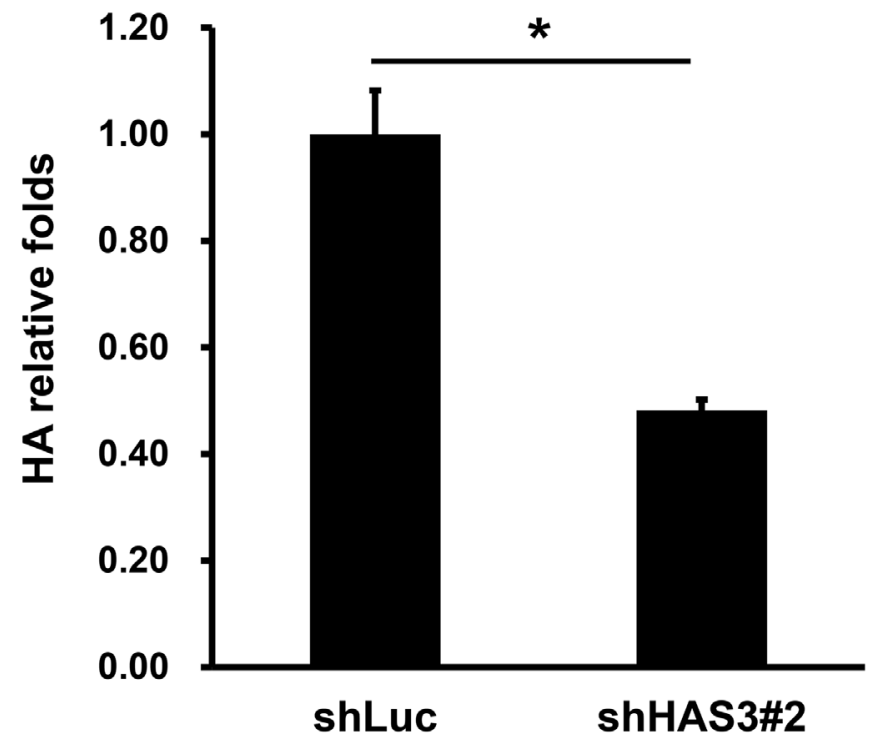

C

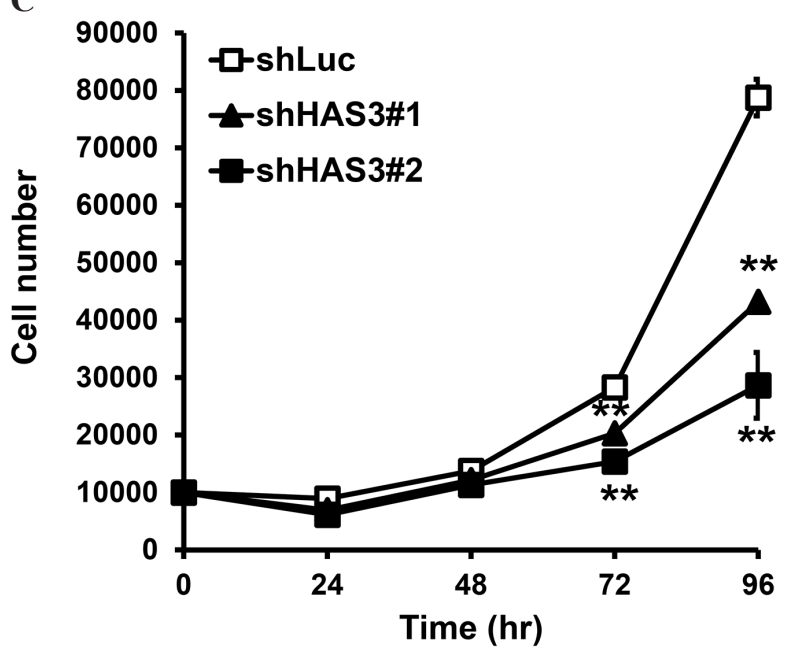

D

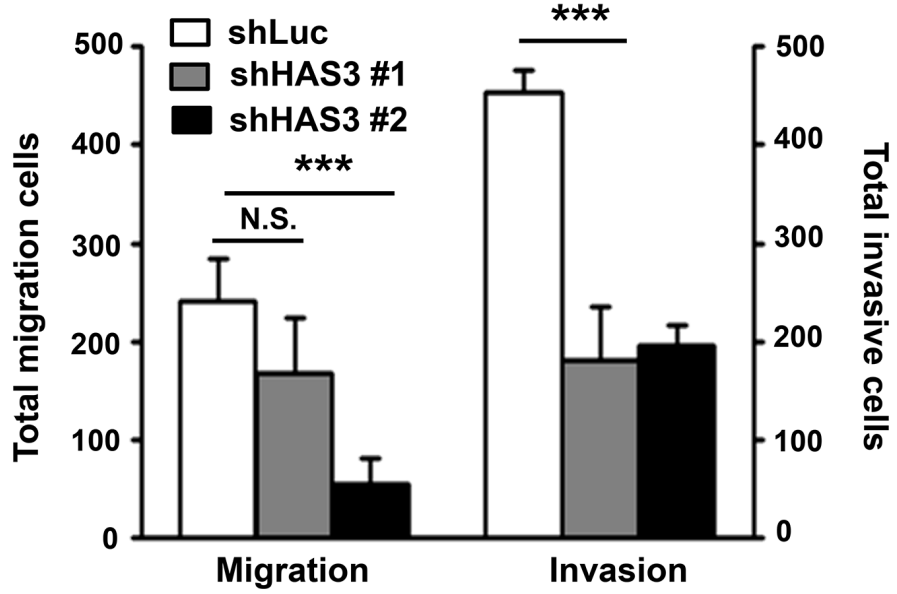

Figure 3: HAS3 silencing reduced HA accumulation, cell proliferation, migration, and invasion. A. Myc-tagged HAS3expressing OC-2 cells (OC-2-HAS3) were infected with lentiviruses bearing shLuc or shRNA-HAS3(clone \#1 or \#2) to deplete HAS3 expression in these cells. Western blot analysis of Myc-tagged HAS3 expression in the indicated knockdown cells. Actin was a loading control. The numbers on the bottom are expression folds relative to shLuc control. This experiment is representative of two biological repeats. B. Following HA concentrations in the indicated CM by using ELISA, HA production was expressed as relative folds following normalization with shLuc control cells. *p<0.05; Student's t test. C. Viable cells in the control shLuc or HAS3-depeleted OC-2 clones were enumerated by cell proliferation assay. D. The migration and invasion abilities of the manipulated cells were measured, respectively, by Transwell migration and matrigel invasion assays. $\mathrm{C}$ and $\mathrm{D}$ are representative of two independent experiments performed in triplicate. $* \mathrm{p}<0.05 ; * * \mathrm{p}<0.01 ; * * * \mathrm{p}<0.001 ;$ N.S, not significant; One-way ANOVA and Tukey’s multiple comparison test. 
A

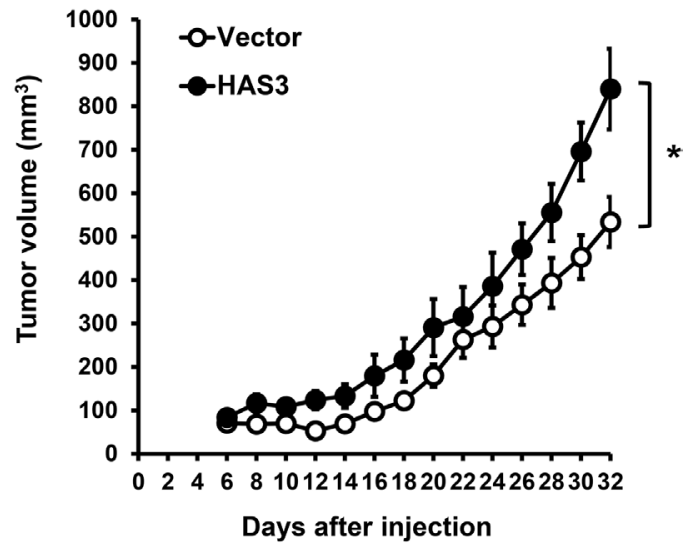

B


C
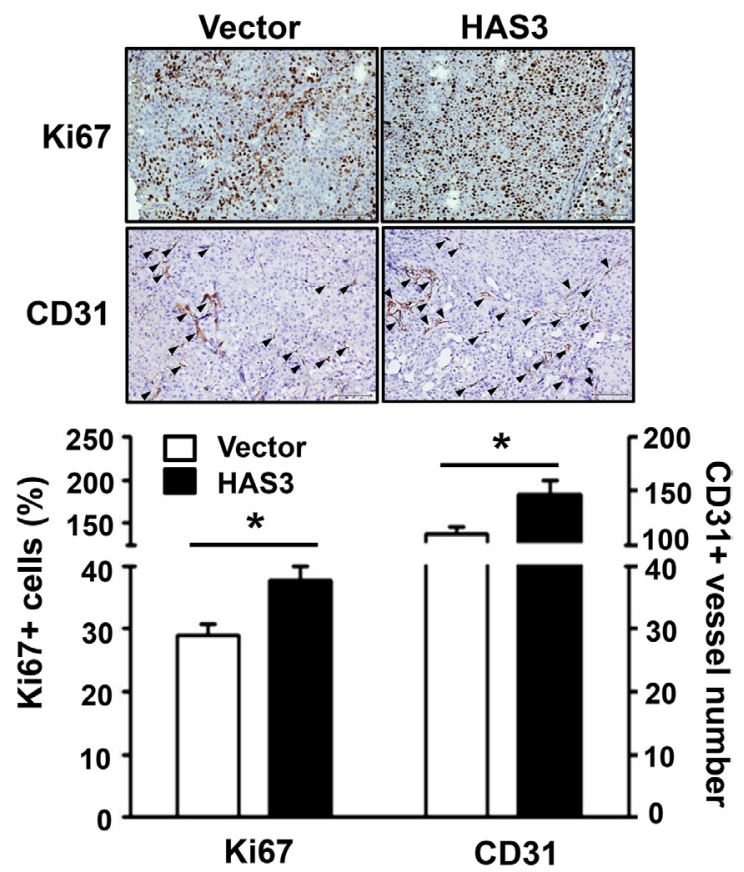

Figure 4: Ectopic HAS3 expression promoted xenograft tumorigenesis in vivo. A. Myc-tagged HAS3- or vector-expressing OC-2 cells were subcutaneously injected into male nude mice ( 10 mice per group). Tumor volume was measured every 2 days for 32 days. B. Tumor images and weights of vector or HAS3 group at the end point. C. Top, representative IHC staining of Ki67 and CD31 (arrowhead) in vector or HAS3-OC-2 tumor sections (200X magnification). Bottom, the percentage of Ki67+ nuclei or the number of $\mathrm{CD} 31+$ microvessels in five random 200X fields of the indicated mouse tissues were expressed as mean \pm SEM. ${ }^{* * *} \mathrm{p}<0.001 ;{ }^{*} \mathrm{p}<0.05$ versus vector. 
expressing cells compared to DMSO control (Figure 5B). Consistent with the basal SRC activation in vector control cells, the attentuation reduced cell proliferation, migration and invasion in not only HAS3-OC-2 but also vector cells (Figure 5C-5E). Together, the activation of SRC-EGFR signaling axis was in part responsible for HAS-3-mediated oncogenic action.

\section{HAS3-derived CM promoted monocyte} recruitment and MCP-1 expression

HA is implicated in monocyte/macrophage trafficking [4, 5]. With the detected HA increase in HAS3-derived CM relative to vector-CM (Figure 2B), we measured the monocytic U937 transendothelial
A

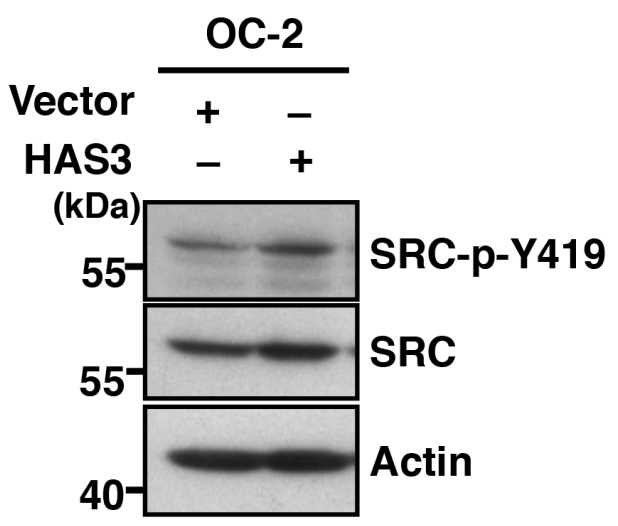

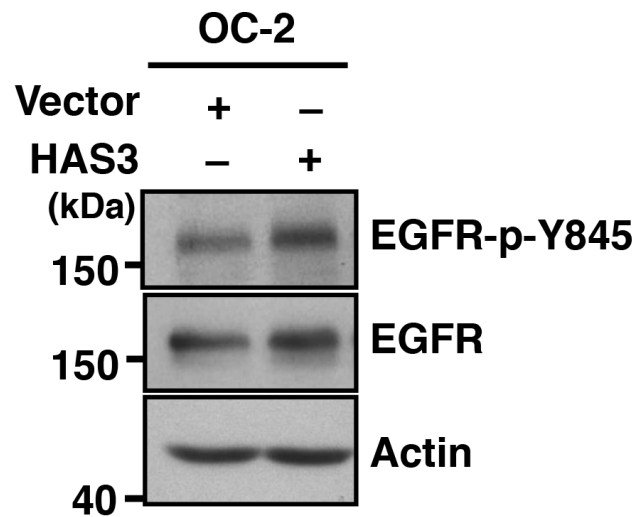
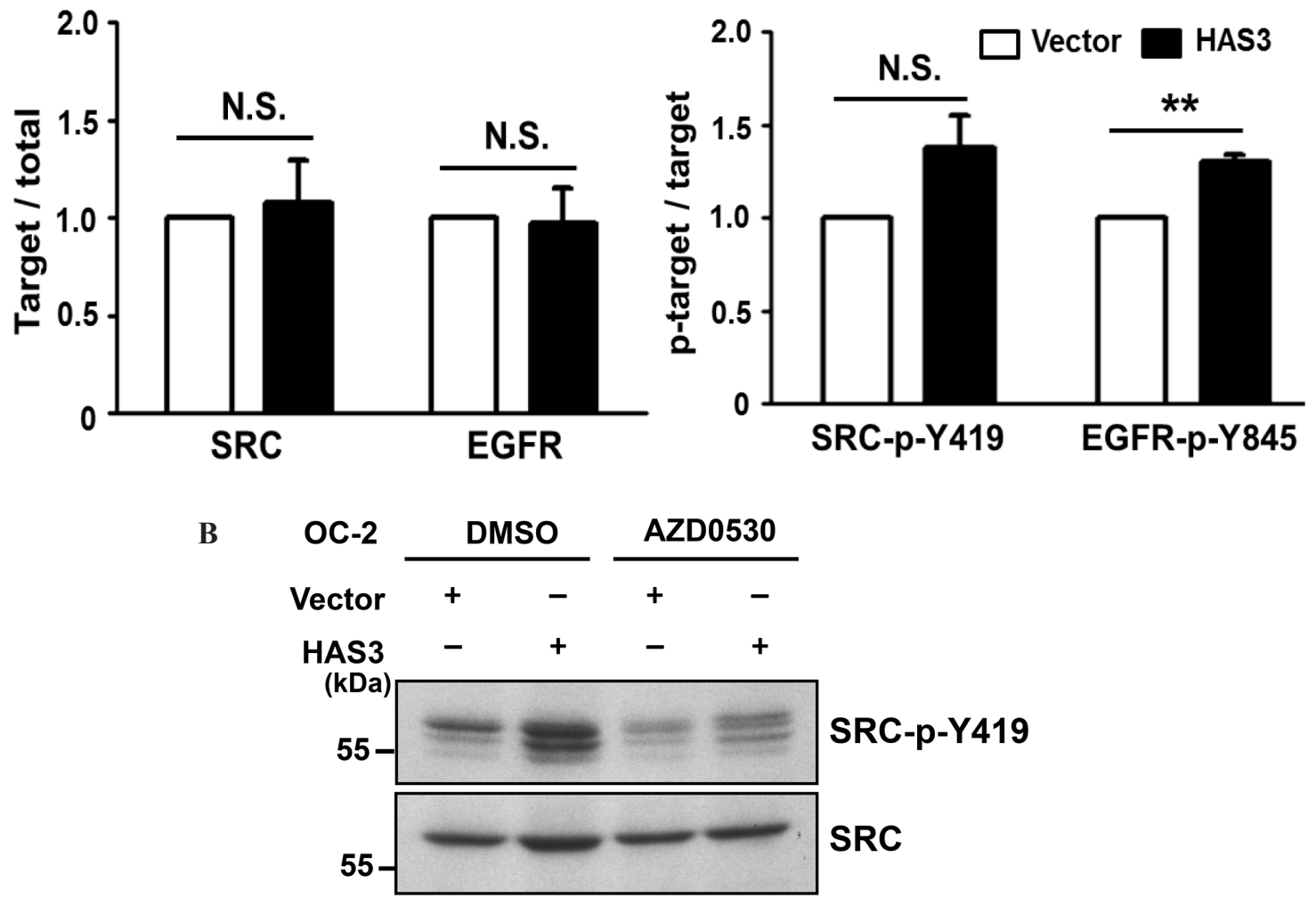

Figure 5: HAS3-mediated oncogenic actions were partly through the activation of Src-EGFR signaling axis. A. Top, the expression levels of Src and its activating phosphorylation at Y419 residue (Left) or those of EGFR and its activating phosphorylation at Y845 (Right) in the OC-2 cells infected with vector or HAS3-bearing lentiviruses. Actin was a loading control. The blot shown is representative of 2 independent experiments. Bottom, the normalized activating phosphorylation of Src and EGFR in the indicated cells was expressed as mean $\pm \mathrm{SD}(\mathrm{N}=3)$. ** $\mathrm{p}<0.01$; N.S, not significant; Student's t test. B. Following DMSO or AZD0530 ( $2 \mu \mathrm{M})$ treatment, the indicated cell lysates were analyzed for Y419 phosphorylation and total level of Src by Western blot analysis. The blot shown is representative of 2 independent experiments.

(Continued) 
C

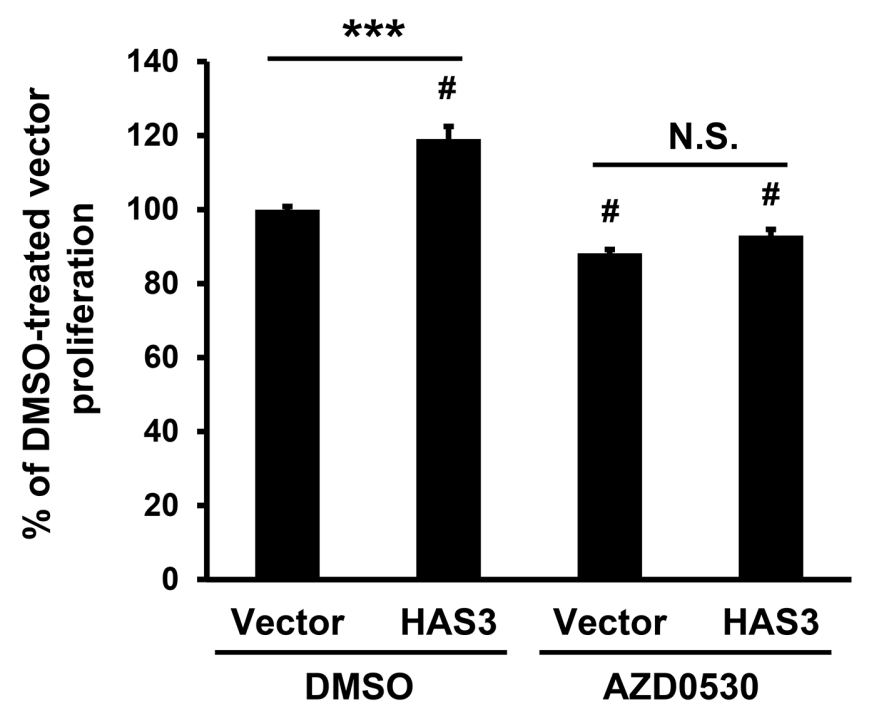

D

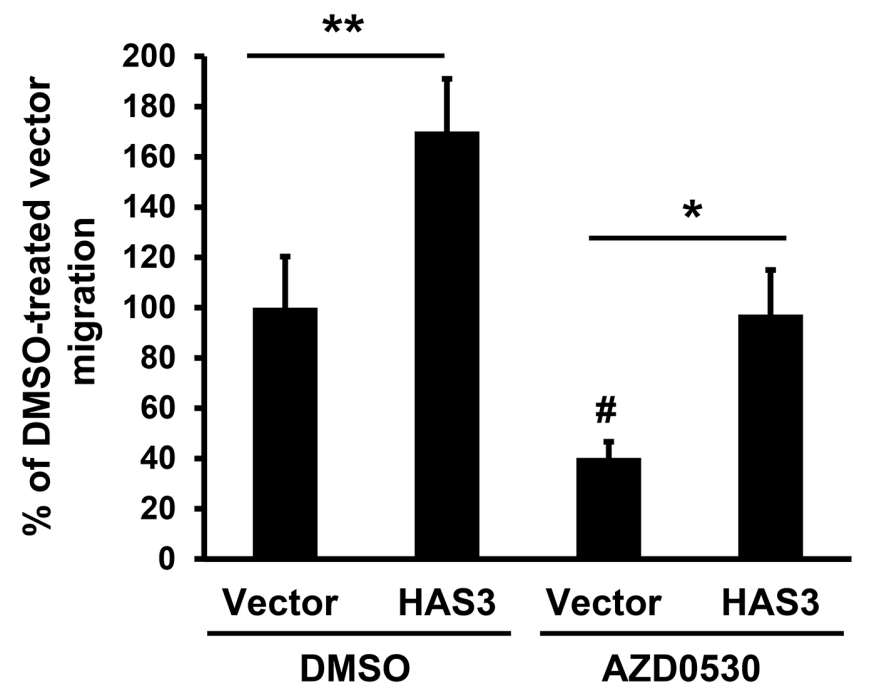

$\mathbf{E}$

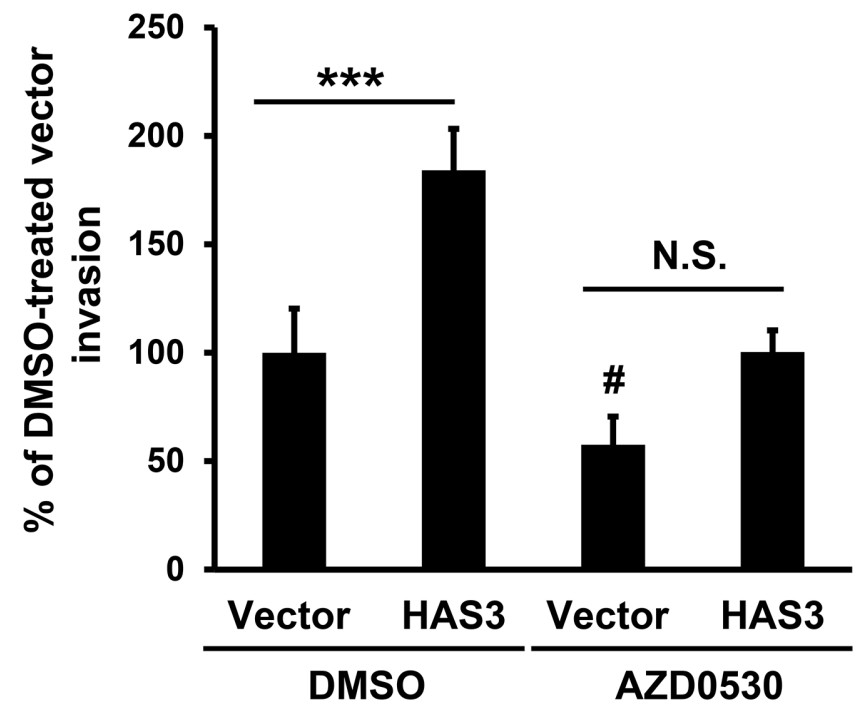

Figure 5 (Continued): C-E. The proliferation, migration and invasion abilities of vector- or HAS3-expressing OC-2 cells in the presence of DMSO (0.1\%) or AZD0530 following normalization with DMSO-treated vector control. Results are representative of two independent experiments performed in triplicate. ${ }^{*} \mathrm{p}<0.05 ;{ }^{* *} \mathrm{p}<0.01 ;{ }^{* * *} \mathrm{p}<0.001$; N.S, not significant. ${ }^{*} \mathrm{p}<0.05$ versus DMSO-treated vector control. One-way ANOVA and Tukey's multiple comparison test. 
migration ability mediated by CM. HAS3-CM increased U937 cell recruitment relative to vector-CM, and HAS3 depletion by shRNA\#2 reduced the stimulation (Figure 6A). The expression of MCP-1, a regulator for monocyte/ macrophage migration and infiltration [28], is inducible by fragmented HA in renal tubular epithelial cells [29]. The recruited monocytes/macrophages can further release pro-inflammatory cytokines like TNF- $\alpha$ to accelerate tumor progression [30]. We analyzed by qRT-PCR if HAS3-CM could affect the expression of MCP-1 and
A

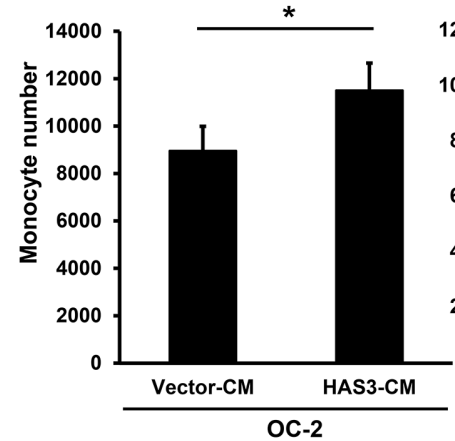

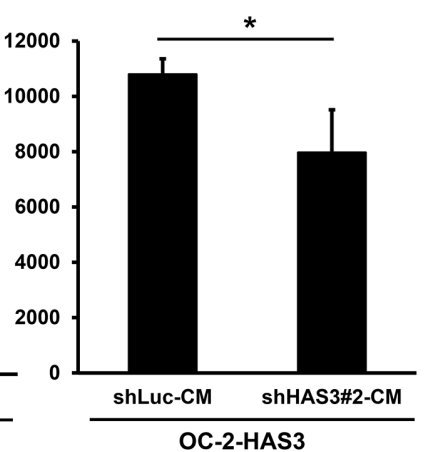

B

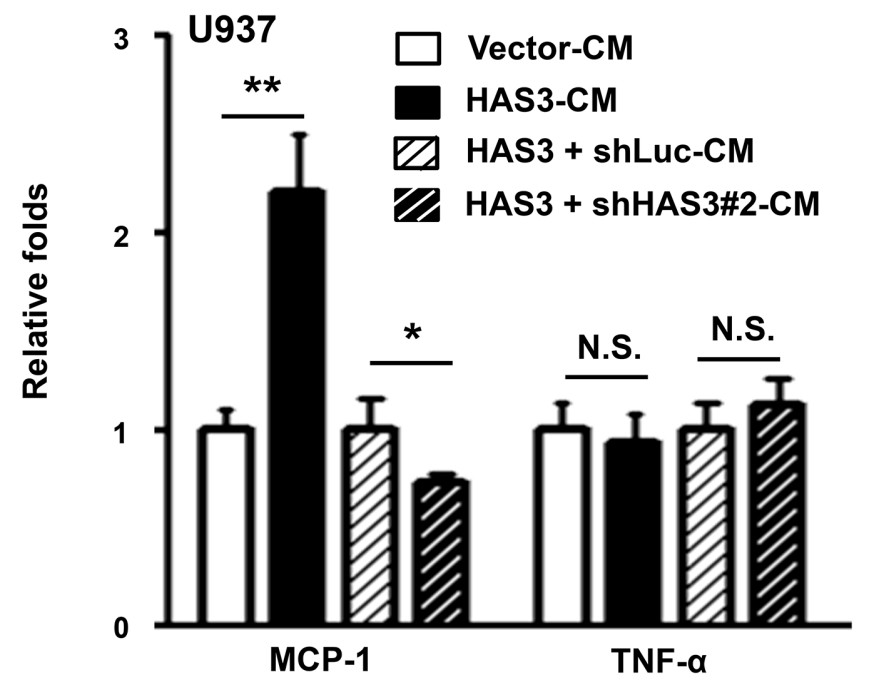

C

Mouse

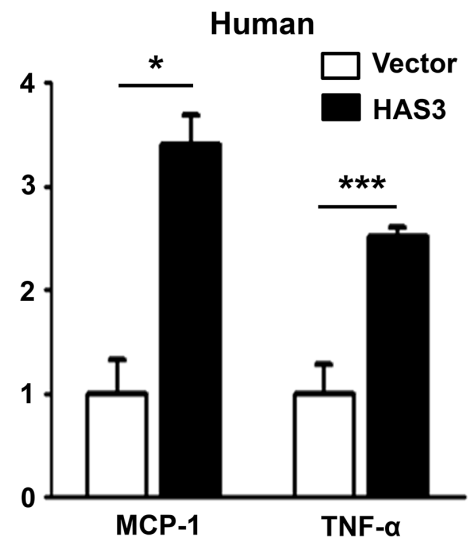

Figure 6: HAS3-altered CM differentially regulated monocyte transendothelial migration and the expression of TNF- $\alpha$ and MCP-1. A. Monocytic U937 cell migration through endothelial monolayer was measured after 24-hr incubation with the indicated CM. Left, CM from vector- or HAS3-OC-2 cells; Right, CM from OC-2-HAS3 infected with shLuc or shHAS3 lentiviruses. B. The expression of MCP-1 and TNF- $\alpha$ was analyzed in triplicate by qRT-PCR after 48-hr treatment of U937 with the indicated CM and expressed as relative folds. A and B results are representative of two independent experiments performed in triplicate. C. The mRNA expression of murine F4/80, MCP-1 and TNF- $\alpha$ in xenograft tumors was analyzed in triplicate by qRT-PCR and expressed as relative folds (Mean \pm SEM, $\mathrm{N}=10$ ). Left, mouse-specific probes. Right, human-specific probes. ${ }^{*} \mathrm{p}<0.05$; ${ }^{*} \mathrm{p}<0.01 ; * * * \mathrm{p}<0.001$; Student's t-test. 
TNF- $\alpha$ in treated U937 cells. The expression of MCP-1 mRNA was significantly up-regulated by HAS3-CM but down-regulated by shHAS3\#2-CM when compared with the indicated control. HAS3-altered CM, however, had no effect on TNF- $\alpha$ expression (Figure 6B).

We also examined the in vivo effect of enforced HAS3 expression on differential regulation of these two cytokines in xenograft tissues. The contribution of macrophages was studied by analyzing the expression of F4/80, a murine macrophage marker [31]. Despite no stimulation of F4/80, MCP-1 or TNF- $\alpha$ mRNA expression from mouse stroma, the expression of human MCP-1 and TNF- $\alpha$ mRNA was significantly increased in HAS3 xenografts relative to that in vector grafts, suggesting the existence of inter-regulation of HAS3 with cytokines in vivo tumors (Figure 6C). Taken together, HAS3-CM increased monocytic transendothelial migration partly through enhanced MCP-1 expression in vitro and in vivo.

\section{A requirement of $\mathrm{HA}$ accumulation for HAS3- mediated oncogenic action}

To examine if HA accumulation in the CM was necessary for the oncogenic action mediated by HAS3, we used pharmacological inhibition or antibody neutralization followed by measuring cell migration, invasion, and monocyte transendothelial migration. MCP-1 mRNA expression in the treated cells was analyzed by qRTPCR. In addition to reducing HA accumulation (Figure 7A), 4-MU (1 mM) or HAS3 neutralization $(10 \mu \mathrm{g} / \mathrm{mL})$ signficantly attenuated oral cancer cell migration and invasion, and decreased HAS3-mediated increase of relative MCP1 expression in oral cancer cells (Figure 7B-7C). Together, the pharmacological inhibition of HAS enzymatic activity or HAS3 neutralization mimicked HAS3 depletion effects on oral cancer cells, supporting that HA accumulation was accountable for oncogenic actions mediated by HAS3.

\section{TNF- $\alpha$-mediated HAS3 transcriptional stimulation through a direct binding of activated $\mathrm{NF}-\kappa \mathrm{B}$ in oral cancer cells}

TNF- $\alpha$ induced HAS3 mRNA expression in skin fibroblasts and ligament cells with no clear mechanism $[32,33]$. We examined by qRT-PCR if TNF- $\alpha$ also stimulated HAS3 mRNA expression in oral cancer cells. OC-2 cells were treated for $3 \mathrm{hrs}$ with recombinant human TNF- $\alpha$ at $1-50 \mathrm{ng} / \mathrm{mL}$ prior to total RNA isolation. TNF- $\alpha$ indeed dose-dependently stimulated HAS3 mRNA expression (Figure 8A, Left). Consistent with the inducing role of TNF- $\alpha$ on canonical NF- $\kappa$ B activation [34], TNF- $\alpha$ induced activating phosphorylation of NF- $\mathrm{B}-\mathrm{p} 65$ at S536 and destabling phosphorylation of $\mathrm{I} \kappa \mathrm{B} \alpha$ at $\mathrm{S} 32$, leading to NF- $\kappa \mathrm{B}$ activation, with a maximal induction at $10-50$ $\mathrm{ng} / \mathrm{mL}$ (Figure 8A, Right). To validate the involvement of NF- $\kappa \mathrm{B}$ activation in HAS3 transcription, OC2 cells were co-treated for $3 \mathrm{hr}$ with TNF- $\alpha(50 \mathrm{ng} / \mathrm{mL})$ and a $\mathrm{NF}-\kappa \mathrm{B}$ inhibitor, pyrrolidine dithiocarbamate (PDTC) or BMS-345541. The pharmacological inhibition of $\mathrm{NF}-\kappa \mathrm{B}$ activation by PDTC $(25 \mu \mathrm{M})$ or BMS-345541 (1-5 $\mu \mathrm{M})$ significantly reduced TNF- $\alpha$-induced HAS3 mRNA expression (Figure 8B), indicating a requirement of canonical $\mathrm{NF}-\kappa \mathrm{B}$ activation for the transcriptional regulation of HAS3 expression.

Due to the presence of 3 published transcripts (variants 1-3) and one alternative transcriptional initiation (variant 4) [35], the HAS3 promoter spanning -4172 and +249 using variant 1 as transcription start site $(+1)$ was divided into 3 segments, P1-P3, which were individually cloned into pGL3-basic luciferase construct. Four putative $\mathrm{NF}-\kappa \mathrm{B}$ binding sites, I-IV, were predicted by using LASAGNA-Search 2.0 in this region (Figure $8 \mathrm{C}$, Top). Promoter-driven luciferase assays showed that P2 harbored the highest basal promoter activity and the

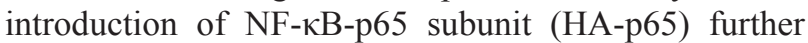
enhanced the activity of all promoter segments (Figure $8 \mathrm{C}$ ). To examine if TNF- $\alpha$ could increase the in vivo NF$\kappa \mathrm{B}$ binding to the HAS3 promoter in oral cancer cells, we performed ChIP-qPCR analysis of NF- $\kappa$ B sites I and II in $\mathrm{P} 1$, III in $\mathrm{P} 2$ and IV in $\mathrm{P} 3$ promoter regions. Following TNF- $\alpha$ stimulation for $3 \mathrm{hrs}$, there was an significant increase in the enrichement of in vivo NF- $\kappa \mathrm{B}-\mathrm{p} 65$ binding to each promoter region. The highest enrichement was in site III for NF- $\kappa \mathrm{B}$ binding $(-1692 \sim-1682)$ in the P2 promoter (Figure 8D). Together, TNF- $\alpha$ induced the transcriptional regulation of HAS3 expression through a direct binding of activated NF- $\mathrm{KB}$ in oral cancer.

\section{The increase of both HAS3 and TNF- $\alpha$ expression was correlated with reduced overall surival}

In addition to TNF- $\alpha$-mediated HAS3 transcriptional induction, chronic TNF- $\alpha$ exposure induced oral cancer cell stemness [36]. However, the relationship between HAS3 and TNF- $\alpha$ expression has never been examined in human cancer patients. Due to the inability of having specific HAS3 protein staining in clinical specimens, we, therefore, investigated the transcript levels of HAS3 and TNF- $\alpha$ in pairwise oral cancer specimens by using qRT-PCR. We first validated that HAS3 was also the most expressed HAS member in 30 clinical tissues (Supplementary Figure 2). The expression of HAS3 or TNF- $\alpha$ mRNA was significantly increased in 86 oral cancer relative to adjacent normal tissues (Figure 9A). Pearson correlation showed a positive association in the increase of both expression in the same specimens (Figure 9B, $\mathrm{p}=0.004$ ). We divided these patients into 2 groups, high $(>$ mean) and low $(\leq$ mean), for its relation with clinicopathologic characteris and Kaplan-Meier survival curve analysis based on the mean HAS3 mRNA 
A

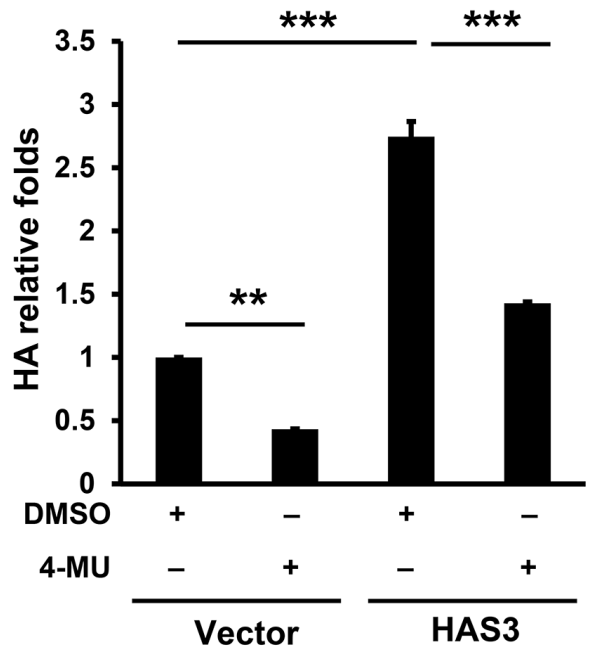

B

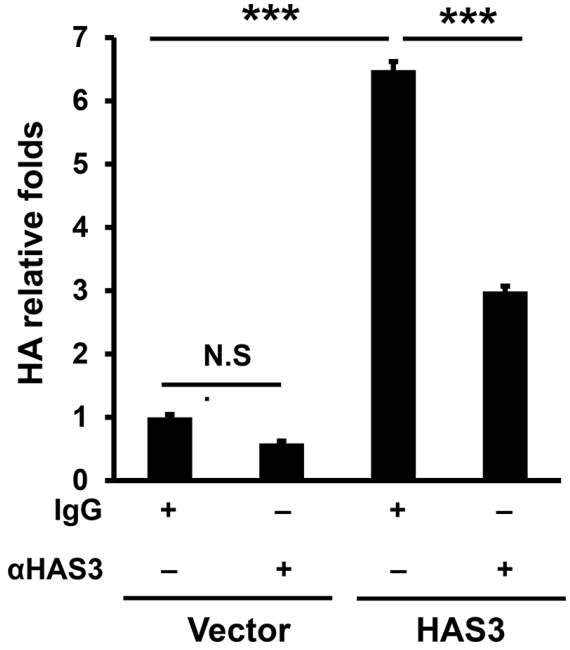

$\square$ Vector + DMSO $\square$ HAS3 + DMSO

$\square$ Vector + aHAS3 U/A HAS3 + aHAS3

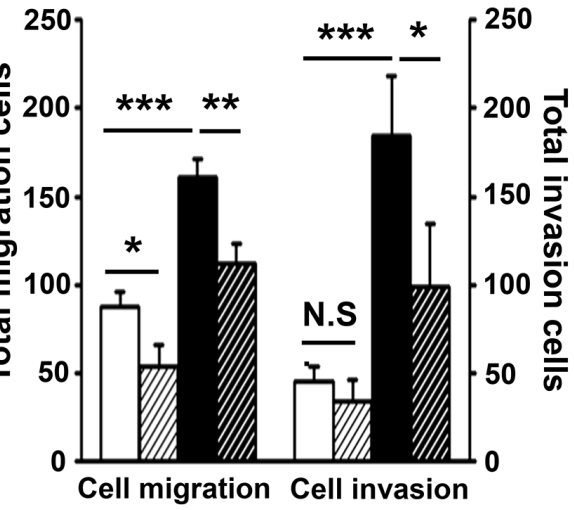

C
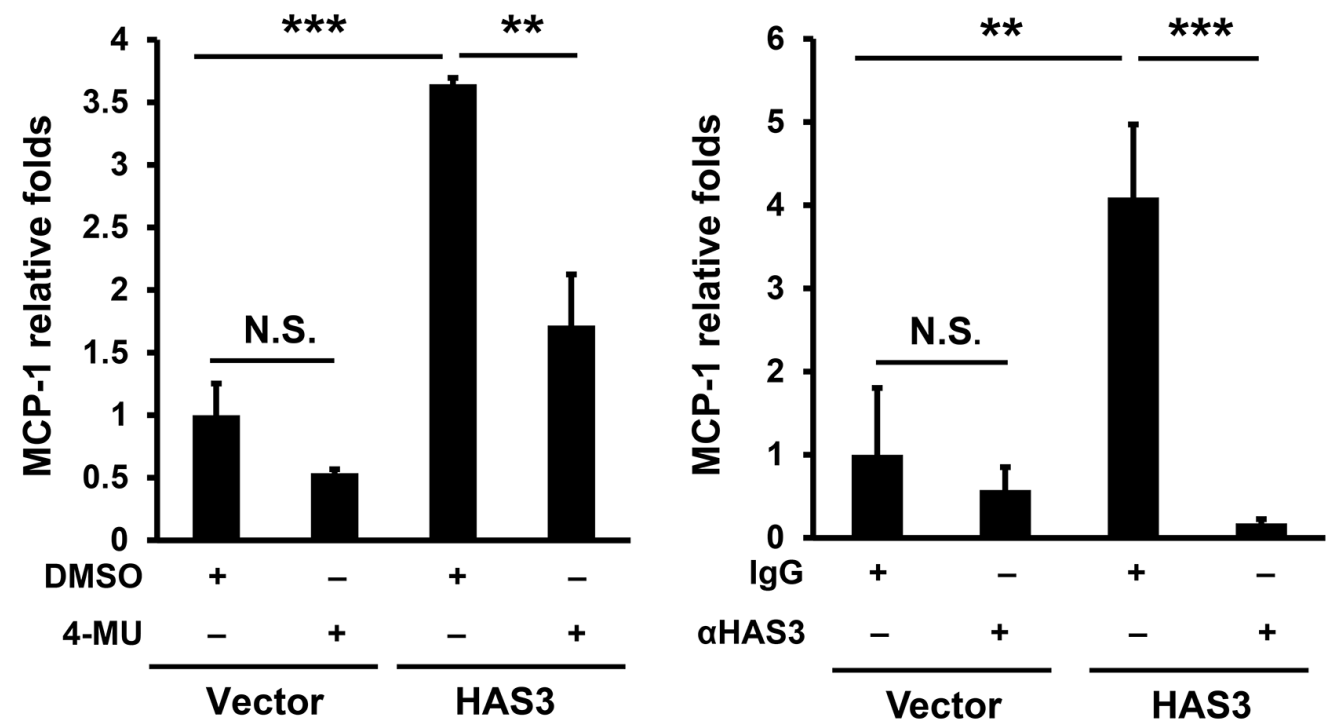

Figure 7: Inhibition of HAS3-mediated HA accumulation reduced the migration, invasion and MCP-1 expression in oral cancer cells. Following the inhibition of HAS3 activity by 4-MU $(1 \mathrm{mM})$ or HAS3 antibodies $(10 \mu \mathrm{g} / \mathrm{mL})$ for $6-24 \mathrm{hrs}$, the treated cells were subjected to A. ELISA for HA accumulation, B. migration and invasion assays and $\mathbf{C}$. for qRT-PCR analysis of MCP-1 expression. HA proudction and MCP-1 expression was expressed as relative folds following normalization with vector control. Results are representative of two independent experiments performed in triplicate. One-way ANOVA and Tukey's multiple comparison test, mean \pm SD. ${ }^{*} \mathrm{p}<0.05 ; * * \mathrm{p}<0.01 ; * * \mathrm{p}<0.001$ 
expression. Although there was no significant association of HAS3 deregulation with any clinicopathologic characteristics (Supplementary Table 1), high HAS3 patients tended to have poor overall survival relative to low HAS3 ones (Figure 9C, Left, $p=0.139$ ). With the increasingly present of HAS3 mRNA in the late stages (Figure 9C, Right), we examined if increased HAS3 mRNA expression had any impact on the overall survival of these patients. High HAS3 expression further reduced the overall survival for late-stage oral cancer patients (Figure 9D, Left, $p=0.073$ ). Since TNF- $\alpha$ may function as a upstream mediator for HAS3 expression in oral cancer, we next studied the correlation of TNF- $\alpha$ deregulation with late-stage patients' clinicopathologic characteristics and clinical outcome. We found that high TNF- $\alpha$ expression in high HAS3 patients was mainly associated with the involvement of lymph nodes (Table 1, $p=0.008$ ) and further reduced their clinical outcome with a borderline $p$ value of 0.052 (Figure 9D, Right). Together, a concordant increase of HAS 3 with TNF- $\alpha$ expression could potentially serve as a poor prognosis signature for oral cancer.

\section{DISCUSSION}

HA is important for tumor progression in several cancer types [22] and its synthesis is correlated with the

A

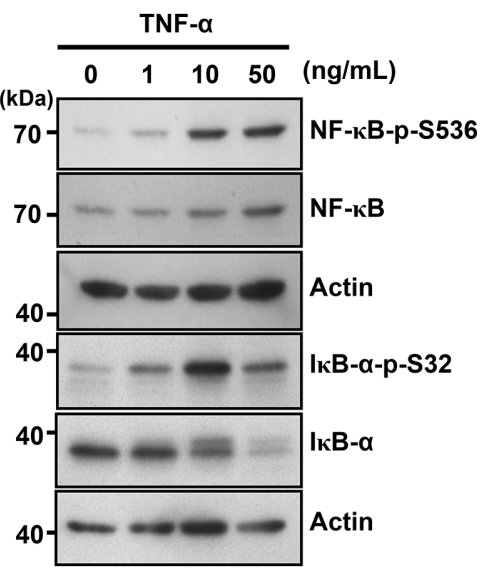

B

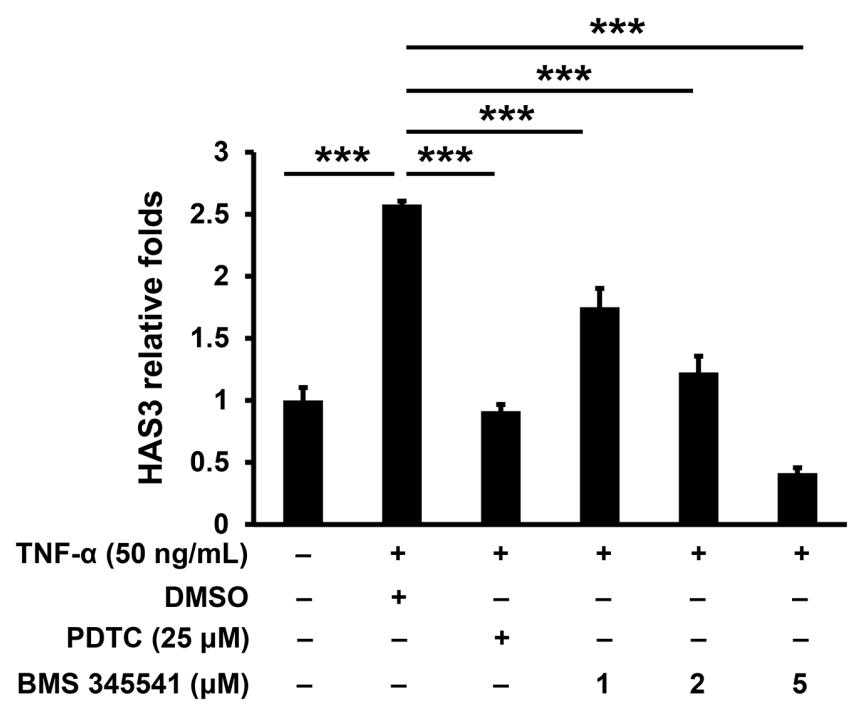

Figure 8: TNF- $\alpha$ mediated transcriptional stimulation of HAS3 expression via direct binding of activated NF- $\mathrm{KB}$. A. Left, the expression of HAS3 mRNA in OC- 2 cells stimulated for 3 hrs with the indicated concentration of TNF- $\alpha$ was measured by qRTPCR and expressed as relative folds. This experiment is representative of two independent ones. ${ }^{* *} \mathrm{p}<0.01 ; * * * \mathrm{p}<0.001$ versus untreated

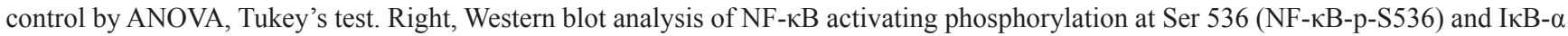
destabling phosphorylation at Ser32 (IкB- $\alpha-\mathrm{p}-\mathrm{S} 32$ ) in OC-2 cells treated for $15 \mathrm{~min}$ with TNF- $\alpha$ at $0-50 \mathrm{ng} / \mathrm{mL}$. B. Following normalization with untreated control cells, the relative folds of HAS3 mRNA in the oral cancer cells treated for $3 \mathrm{hr}$ with TNF- $\alpha(50 \mathrm{ng} / \mathrm{mL}) \mathrm{in}$ the presence of a NF- $\kappa \mathrm{B}$ inhibitor, PDTC $(25 \mu \mathrm{M})$ or BMS-345541 (1-5 $\mu \mathrm{M})$.

(Continued) 



D
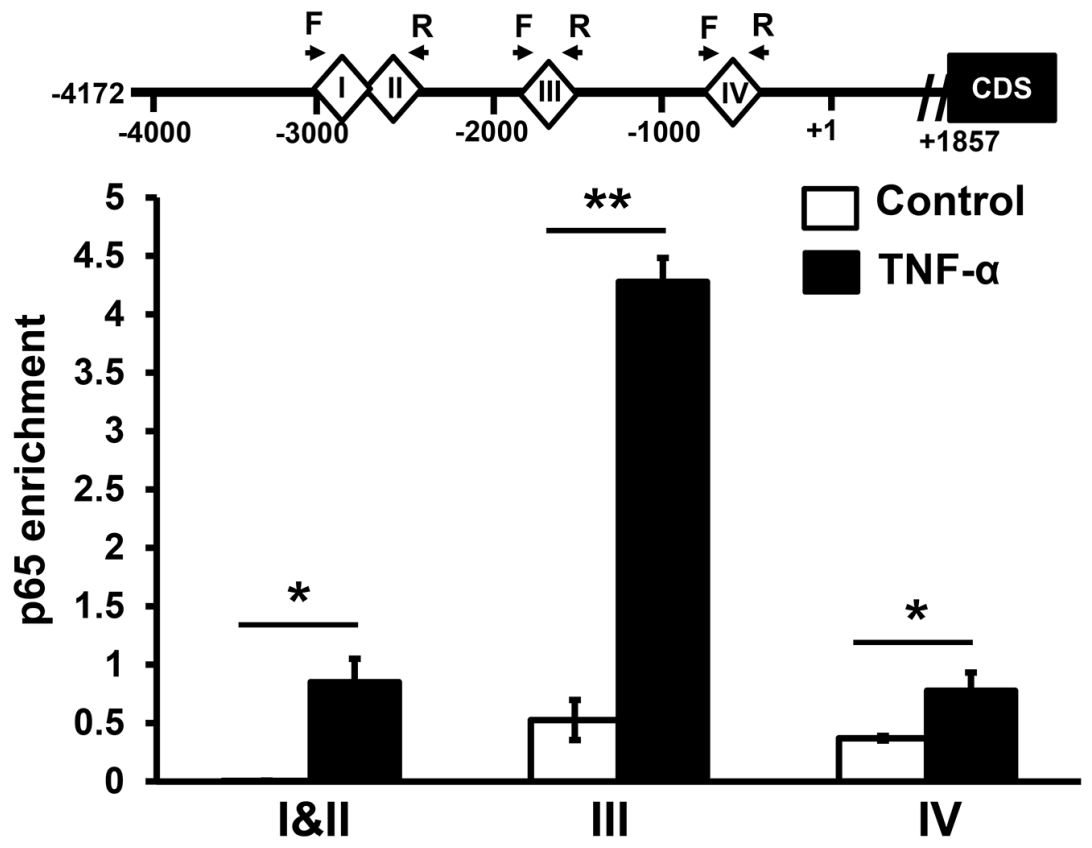

Figure 8 (Continued): C. Top, schematic drawing of the consensus sequence and 4 putative binding sites I-IV for NF- $\kappa B$ binding, and the initiation sites for 4 transcript variants, V1-V4, in the proximal HAS3 promoter spanning from -4172 to +249 . This $4-\mathrm{kb}$ promoter was divided into 3 segments, P1-P3, for the luciferase reporter assay. We measured relative luciferase activities in the OC-2 cells tranisently transfected with the indicated promoter constructs, P1-P3, in the absence or presence of NF-kB-p65 subunit (HA-p65). The indicated promoter activity was shown in the bottom as the induction fold following normalization with pGL3-Basic vector activity in oral cancer cells (Mean $\pm \mathrm{SD}$ of 3 repeats). ${ }^{*} \mathrm{p}<0.01 ; * * * \mathrm{p}<0.001$ versus the indicated control. D. ChIP-qPCR analysis showed the enrichement of $i n$ vivo NF- $\kappa \mathrm{B}-\mathrm{p} 65$ binding to the indicated $\mathrm{NF}-\kappa \mathrm{B}$ site in $\mathrm{P} 1-\mathrm{P} 3$ promoter region upon TNF- $\alpha$ stimulation for $3 \mathrm{hrs}(\mathrm{N}=2)$. ${ }^{*} \mathrm{p}<0.05 ; * * \mathrm{p}<0.01$; Student's t test. 
A

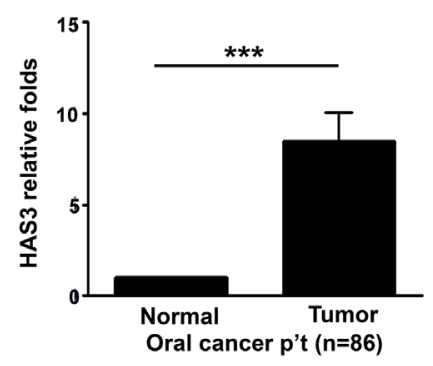

B

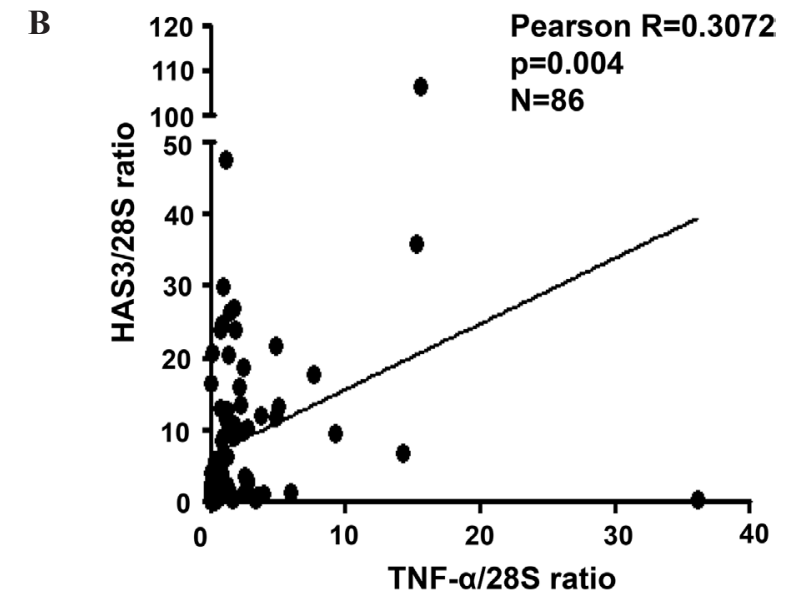

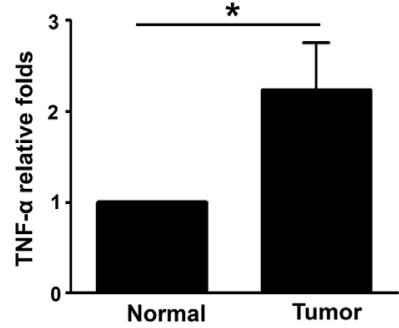

Oral cancer p’t $(n=86)$

C


D


Figure 9: A positive correlation of HAS3 with TNF- $\alpha$ expression in oral cancer. A. The relative expression of HAS3 (Left) and TNF- $\alpha$ (Right) mRNA in 86 pairwise surgical specimens including tumor and normal tissues was measured by qRT-PCR. Each experiment was carried out in triplicate. Data are Mean \pm SEM. $* * p<0.01 ; * p<0.05$ vs normal. B. Pearson correlation analysis showing a positive correlation of HAS3 and TNF- $\alpha$ expression in tumor specimens. C. Left, Kaplan-Meier survival curve analysis of 86 oral cancer patients with high $(>$ mean) or low $(\leq$ mean) HAS3 expression. Right, the relative folds of HAS3 mRNA expression in early and late stage oral cancer patients. D. Left, Kaplan-Meier analysis showed that late-stage oral cancer patients with high expression of both HAS3 and TNF- $\alpha$ expression had reduced overall survival relative to those with both low expression $(p=0.073)$. Right, the concordant increase of HAS3 with TNF- $\alpha$ expression in oral cancer patients had poorest overall survival $(\mathrm{p}=0.052)$. 
Table 1: Mean HAS3 and TNF- $\alpha$ expression in relation to clinicopathologic characteristics of oral cancer

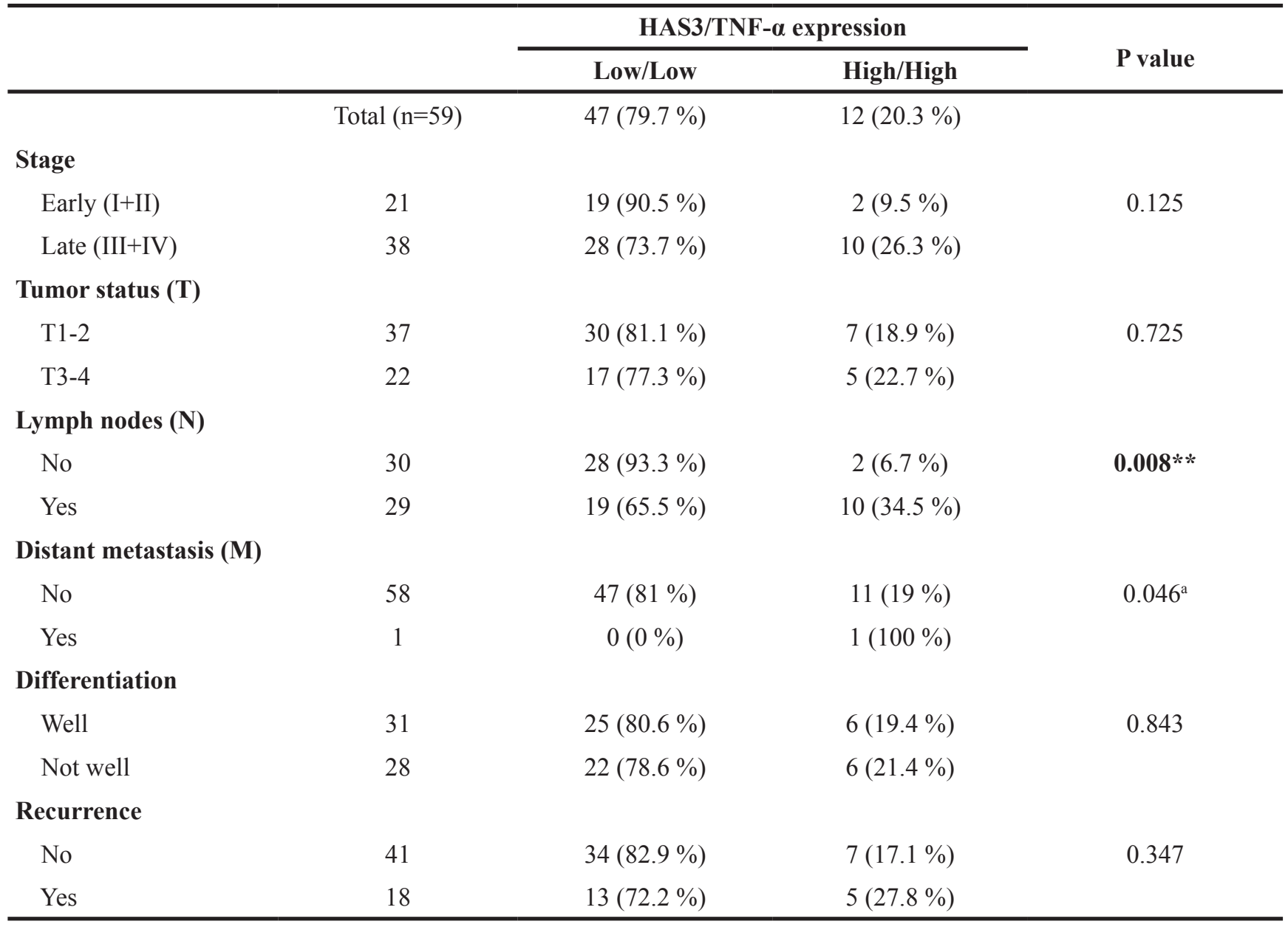

$* * p<0.01$ by Chi-square test.

a, only 1 case with distant metastasis.

expression of HAS family members [37]. In this study, HAS3, the most abundant member in oral cancer cells, was increasingly present in oral cancer tissues compared to their normal counterparts. The increase of HAS3 expression predominantly promoted oral cancer migration and invasion in vitro and xenograft tumorigenesis in vivo. HAS3 depletion negated the oncogenic actions. SRCEGFR signaling axis was activated in HAS3-mediated oncogenic actions. HAS3-derived HA accumulation increased transendothelial migration of monocytes possibly through induction of MCP-1 expression. TNF- $\alpha$, frequently overexpressed in advanced oral cancer tissues [38], functioned as an upstream inducer for HAS3 transcriptional expression partly through NF- $\kappa B$ activation. The increase of both HAS3 and TNF- $\alpha$ mRNA expression was correlated with decreased overall survival for oral cancer patients.

In addition to HAS3, HAS1 or HAS2 was also implicated in human malignancy [39, 40]. Despite the detection of both HAS1 and HAS2 in oral cancer cells, their expression levels were lower than that of HAS3 in most oral cancer cell lines (Figure 1A) not to mention that HAS1 and HAS2 are catalytically less active than HAS3 in HA synthesis [41]. The predominant HAS3 expression was also validated by qRT-PCR analysis in clinical oral cancer specimens regardless of the presence of stromal cells (Supplementary Figure 2). Over-expression and knockdown experiments together with a pharmacological inhibition and anti-HAS3 antibody blockage supported an oncogenic role of HAS3 in oral cancer. Although HAS3 appears to play a dominant role in oral cancer, we still can not rule out the involvement of HAS1 or HAS2 in HA synthesis nor explain why reduced HA staining was a poor prognositic maker in other oral cancer cohort [20]. More studies are needed to examine the differential contribution of HAS1-3 to HA synthesis in oral cancer.

Among many cell surface receptors for HA-mediated signaling [42], HA bound CD44 receptor critically mediates tumor cell growth, survival, migration, and metastasis [43]. Consistent with the HA-mediated activation of SRCEGFR signaling axis [25, 26], HAS3 overexpression also increased the levels of SRC-p-Y419 and EGFR-p-Y845. 
Pharmacological reduction of SRC activity by AZD0530 significantly impaired HAS3-mediated promotion of oncogenic action. We also detected a negative effect of AZD0530 on vector control cells. The reason could be twofold. First, vector OC2 cells had constitutive SRC activation (Figure 5A) as well as endogenous HAS3 expression (Figure 1C). Second, AZD530 inhibited not only SRC but also its related kinases like ABL [44]. More studies are needed to verify if CD44 is the sole receptor for HA and the involvement of additional SRC-related kinases in HAS3-mediated oncogenic signal axis in oral cancer.

The amount of HA was altered accordingly in the CM derived from HAS3-manipulated oral cancer cells (Figure 2B and 3B). Fragmented HA induced MCP-1 expression in renal epithelial cells [29]. A concordant expression of MCP1 with HAS3 in HAS3-manipulated oral cancer cells further supported a positive role of HAS3 on MCP1 expression. LMM-HA could activate macrophages via enhanced TNF- $\alpha$ secretion [45] or increased TNF- $\alpha$ expression in chondrocytes [46]. In addition to the production of pro-inflammatory short chain HA by HAS3 $[1,7]$, the expression of HAS3 was regulated by several cytokines including TNF- $\alpha$ in nonepithelial cells [33]. In contrast to MCP1, we only detected human TNF- $\alpha$ increase in the HAS3 xenograft tissues but not in HAS3-derived CM-treated monocytes (Figure 6B and 6C). The increased TNF- $\alpha$ expression was also observed in HAS3-overexpressing oral cancer cells by qRT-PCR (data not shown). The inter-regulation of HAS3 and cytokines adds another layer of complexity in reglating HAS3 expression in cancer.

Constitutive TNF- $\alpha$ production is a characteristic for many malignant tumors [47], and linked to all steps of tumorigenesis in many cancer types [48]. Consistent with a positive role of TNF- $\alpha$ on NF- $\kappa \mathrm{B}$ activity [49] and a potential mediation of HAS3 expression by $\mathrm{TNF}-\alpha$, we detected a dose-dependent increase of HAS3 mRNA expression and canonical NF- $\kappa \mathrm{B}$ activation in TNF- $\alpha$-treated oral cancer cells. The pharmacological inhibition of NF- $\kappa \mathrm{B}$ activity significantly impaired the stimulation by TNF- $\alpha$. The in vivo binding of NF- $\mathrm{B}-\mathrm{p} 65$ was highly enriched on the site III (-1692 -1682) in the most active P2 promoter that is identical to the recently identified HAS3 core promoter [35]. This study confirmed for the first time that TNF- $\alpha$ with its downstream effector $\mathrm{NF}-\kappa \mathrm{B}$ activity is a potential inducer for HAS3 overexpression in oral cancer.

TNF- $\alpha$ is normally not detectable in plasma or serum of healthy individuals but can be detected in some cancer patients, almost invariably those with advanced disease and poor prognosis [47]. Consistent with TNF- $\alpha$ being an upstream mediator for HAS3 expression, the expression of HAS3 was positively correlated with that of TNF- $\alpha$ in oral cancer specimens. Despite no significant correlation of increased HAS3 expression with reduced patient clinical outcome or with any clinicopathologic characteristic, a concordant increase of both TNF- $\alpha$ and HAS3 expression not only was associated with lymph node metastasis but also further reduced overall survival among late-stage oral cancer patients. Since other cytokines also regulate HAS3 expression [33], their contribution to increasing HAS3 expression in oral cancer remains to be studied.

In summary, HAS3-mediated HA behaved as a stimulus to trigger intracellular signal transduction pathways, which converge to promote biological activities necessary for cell migration and invasion in oral carcinogenesis. TNF- $\alpha$ and HAS3 formed an interregulation loop in mediating oral cancer malignancy via NF- $\kappa \mathrm{B}$ activation (Figure 10). Understanding the

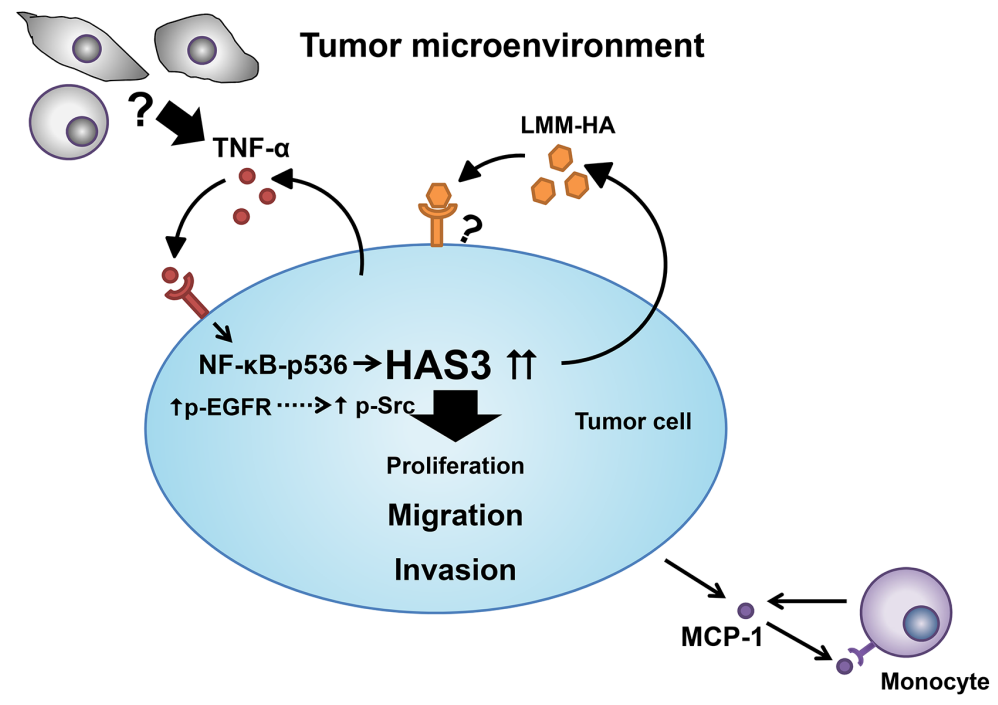

Figure 10: A schematic model for HAS3-mediated oncogenic signaling in tumor microenviroment. The binding of HA secreted by HAS3 to cell surface receptors predominantly enhances cell migration and invasion by triggering EGFR-Src signaling axis in tumor cells. Tumor cell-derived HA stimulates MCP-1 release, and recruites monocytes to the microenvironment. Within the tumor microenvironment, proinflammatory TNF- $\alpha$ from tumor cells or other stromal cells drives the expression of HAS3 in tumor via NF- $\mathrm{BB}$ activation. 


\begin{tabular}{|c|c|c|}
\hline \multirow{2}{*}{ Gene } & \multicolumn{2}{|c|}{ Primer sequence } \\
\hline & Human & Murine \\
\hline \multirow{2}{*}{ HAS1 } & F :5'-GGAGATTCGGTGGACTACG-3' & \\
\hline & R: 5'-TAGGAAGCTGACCCAGGAG-3' & \\
\hline \multirow{2}{*}{ HAS2 } & F: 5'-CATGTACACAGCCTTCAGAG-3' & \\
\hline & R: 5’-GGCTGGGTCAAGCATAGTG-3' & \\
\hline \multirow{2}{*}{ HAS3 } & F: 5’-ATCCAGGTGTGCGACTCTG-3’ & \\
\hline & R: 5'-CACACAGCCAAAGTAGGAC-3' & \\
\hline \multirow{2}{*}{ TNF- $\alpha$} & F: 5'-CCCAGGGACCTCTCTCTAATC-3' & F: 5'-GCCTCTTCTCATTCCTGCTTG-3' \\
\hline & R:5'-ATGGGCTACAGGCTTGTCACT-3’ & R: 5'-GATGATCTGAGTGTGAGGGTCT-3' \\
\hline \multirow{2}{*}{ МCP-1 } & F: 5'-GCCTCCAGCATGAAAGTCTC-3' & F: 5'-AACTCTCACTGAAGCCAGCTCT-3' \\
\hline & R: 5'-AGGTGACTGGGGCATTGAT-3' & R : 5'-CGTTAACTGCATCTGGCTGA-3' \\
\hline \multirow{2}{*}{ F4/80 } & & F: 5'-AGCATCCGAGACACACACAG-3' \\
\hline & & R: 5'-GGCAAGACATACCAGGGAGA-3' \\
\hline \multirow{2}{*}{ NF-кB II (-2692 -2682) } & F: 5’-GACTGAGGTGTGAGGTCTG-3' & \\
\hline & R: 5'-TCTCGCAAGTTTTAGGGGCT-3' & \\
\hline \multirow{2}{*}{ NF-кB III (-1692 -1682) } & F: 5’-TTCCTTGCAGGGTGAGTAG-3’' & \\
\hline & R: 5'-ACCTAGAACCTGAAGCGTC-3' & \\
\hline \multirow{2}{*}{ NF-кB IV (-565 -555) } & F: 5’-TTTCGGAGGCTTGATGGAG-3’ & \\
\hline & R : 5'-CCAGCCCAGGCAAACTAAC-3' & \\
\hline
\end{tabular}

inter-regulation of HA, TNF- $\alpha$, and HAS3 in oral cancer might facilitate the development of novel therapeutics for treating this disease and many other critical diseases associated with HA deregulation.

\section{MATERIALS AND METHODS}

\section{Antibodies and reagents}

Keratinocyte serum-free medium (KSFM), other culture media, fetal bovine serum (FBS), Lipofectamine 2000, TRIzol and qRT-PCR reagents were from ThermoFisher Scientific (Grand Island, NY, USA). Oligonucleotide primers for sequencing and qRT-PCR (Table 2) were from MDbio (Taipei, Taiwan). CellTiter 96® AQueous One Solution (MTS kit) and Dual Luciferase reporter assay were from Promega (Madison, WI, USA). pLKO_AS2.zeo was from National RNAi Core facility in Academia Sinica, Taiwan. The 24-well Millicell culture inserts were from Millipore EMD (Darmstadt, Germany). Anti-CD31 antibodies were from Abcam (Cambridge, MA, USA). Matrigel was from BD Biosciences (Bedford, MA, USA). Recombinant human TNF- $\alpha$ was from Peprotech (Rehovot, Israel). PDTC and BMS-345541 were from Tocris Bioscience (Avonmouth, Bristol, UK). The sources and clone names for the used antibodies were listed in Supplementary Table 2.

\section{Patient specimens}

Oral cancer specimens were from 86 treatment-naive patients (median age $=52$ ) with 7 females and 79 males undergoing surgery at NCKU hospital. Written informed consent was provided by all participants. With the patients' informed consent, the biopsies of histologically proven normal tissue in oral cavities other than tumor sites were taken as pair-wised normal controls. All the fresh samples were handeled anonymously, snap-frozen and stored in liquid nitrogen until use. This study was conducted with the approval of the Institutional Review Board at National Cheng Kung Uniersity. All participants gave consent to participate the study and for publication.

\section{Cell culture}

Normal oral keratinocytes (NOK) from gingival tissues of healthy individuals with informed consent were grown in KSFM [50]. Displastic oral keratinocytes (DOK), one gingival cancer line, OEC-M1, two tongue cancer lines, CAL-27 and HSC-3, and three buccal mucosa cancer lines, OC-2, OC-3, and TW-2.6 were maintained as described [51, 52]. Tongue cancer SAS line (RCB1974) was acquired from RIKEN BioResource Center. Human 293 T and monocytic U937 cells were maintained as described by American Tissue Culture Collection. 


\section{Plasmid constructs}

The HAS3 coding sequence-bearing PCR product spanning from nucleotides 225 to 1886 (Genebank Accession number NM 001199280.1) was cloned into pcDNA3.1(-)/Myc-His A (Invitrogen) and sequenceverified. The Myc/His-tagged HAS3 cDNA fragment was then cloned into pLKO-AS2.zeo lentiviral vector.

\section{HAS3-expressing stable clone establishment}

Vector and HAS3-bearing lentiviruses were prepared from transfection of human 293T cells, respectively, with pLKO-AS2.zeo (Vector) or pLKO-AS2.zeo-HAS3 plasmid using Lipofectamine 2000. Viral particles were collected at $48 \mathrm{hrs}$ post-transfection. Following infection with the indicated lentiviruses at the multiplicity of infection $(\mathrm{MOI}=2)$, stable vector or HAS3-expressing cells were enriched with zeocin $(200 \mu \mathrm{g} / \mathrm{mL})$ for $1-2$ weeks before the indicated experiments.

\section{HAS3 knockdown in oral cancer cells}

HAS3-expressing OC-2 cells were established by infection with shRNA-bearing lentiviruses targeting to Luc (control) or HAS3 sequence $(\mathrm{MOI}=2)$. The shRNA clones targeting to HAS3 protein coding sequence, GCTCTACAACTCTCTGTGGTT (TRCN0000045408, clone\#1) or CCATTGCTACCATCAACAAAT (TRCN0000045409, clone\#2), were from a human library TRC-Hs 1.0 from RNAi Consortium.

\section{qRT-PCR}

Total RNA was isolated by using TRIzol from the indicated cells or snap-frozen tissues. One $\mu \mathrm{g}$ RNA was reverse-transcribed into cDNA using High Capacity cDNA Reverse Transcription Kit (Applied Biosystems, Foster City, CA, USA). We amplified cDNA samples in triplicate by using SYBR Green PCR Master Mix (Roche, West Sussex, UK) and determined the cycle threshold $(\mathrm{Ct})$. Target mRNA expression was calculated by using $2^{-\Delta \mathrm{Ct}}$ $\left(\Delta \mathrm{Ct}=\mathrm{Ct}_{\text {target gene }}-\mathrm{Ct}_{28 \mathrm{~S} \text { rRNA }}\right)$ following the normalization of $28 \mathrm{~S}$ rRNA as an internal control. When comparing target mRNA expression in two different samples, we used $2^{-\Delta \Delta C t}$ as relative fold change as described [53].

\section{Western blot analysis}

Cells were lysed in boiled lysis buffer containing $1 \%$ SDS and $10 \mathrm{mM}$ Tris- $\mathrm{HCl}(\mathrm{pH}$ 7.4). Following concentration measurement by Bradford Protein Assay (Bio-Rad Laboratories, Hercules, CA, USA), equal amounts of total cellular protein were fractionated by SDSPAGE and blotted onto a PVDF membrane. The blot was probed with the indicated primary antibody followed by a horseradish peroxidase-conjugated secondary antibody in the blocking buffer containing $20 \mathrm{mM}$ Tris- $\mathrm{HCl}$ (pH7.5), $150 \mathrm{mM} \mathrm{NaCl}, 0.1 \%$ Tween-20, and $5 \%$ non-fat milk. For detecting protein phosphorylation, the milk was replaced with $3 \%$ bovine serum albumin. The dilution and clone information of antibodies used for hydrization was in Supplementary Table 1. The immunocomplex was detected by Immobilon Western Chemiluminescent HRP substrate (Darmstadt, Germany).

\section{CM preparation}

Subconfluent cells were refed with serum-free culture medium one day after seeding. CM was harvested at $24 \mathrm{hrs}$ after incubation and centrifuged at $3000 \mathrm{rpm}$ to remove cell debris. We used Vivaspin 6 columns (5 kDa MWCO, GE Healthware, Piscataway, NJ, USA) to concentrate the CM.

\section{Cell proliferation assay}

The indicated cells were seeded in triplicate at $10-20 \%$ confluence in 24-well plates. Viable cells were numerated daily by trypan blue exclusion for 4 days postseeding. Alternatively, the cells were quadruplicately seeded at 6000/well for $24 \mathrm{hrs}$ in 96-well plates followed by $\mathrm{CM}$ treatment for $48 \mathrm{hrs}$. Proliferating cells were measured by MTS kits. We independently repeated this experiment 3 times.

\section{Trans-well migration or invasion assay}

These assays were performed in triplicate using 24well Millicell culture inserts with $8 \mu \mathrm{m}$-pore polycarbonate membranes. The indicated cells $\left(3 \times 10^{5} /\right.$ well $)$ were added to upper chambers with membranes coated or not coated with $100 \mu \mathrm{g}$ of Matrigel. Lower chambers were filled with $500 \mu \mathrm{L}$ of growth medium. Uncoated filters were used to measure cell migration ability for $6 \mathrm{hrs}$, whereas coated filters were used for cell invasion for $24 \mathrm{hrs}$. After 6-24 hrs incubation, the cells that migrated to the lower surface were stained with Giemsa solution and counted in high power fields under a microscope. Both assays were independently repeated two times.

\section{Xenograft tumorigenesis and IHC staining}

The use of male BALB/cAnN.Cg-Foxnlnu/CrlNarl mice (6-8 weeks old) from National Laboratory Animal Center in Taiwan were approved by the Institutional Animal Care and Use Committee. Vector- or HAS3-expressing OC-2 cells $\left(2 \times 10^{6}\right)$ with $50 \mu \mathrm{g}$ Matrigel were subcutaneously injected into the flanks of nude mice (10 mice/group). One week after injection, tumor sizes were measured every 2 days for 32 days. Tumor tissues were harvested at the endpoint for IHC staining and RNA/protein isolation following weight measurement. The numbers of Ki67+ and total nuclei as well 
as CD31+ microvessels in 5 random fields were counted by using Image J software.

\section{HA measurement by ELISA}

The HA concentrations in CM were measured in triplicate by Hyaluronan DuoSet ELISA kits (R\&D systems, Minneapolis, MN, USA) with two independent repeats.

\section{Transendothelial migration of monocytes}

HMEC-1 cells $\left(1.5 \times 10^{5} /\right.$ well $)$ seeded in triplicate on collagen-coated Millicell culture inserts were grown to confluence for 3 days. Monocytic U937 cells $\left(10^{4} /\right.$ well) were seeded onto the inserts with TNF- $\alpha$-activated or untreated endothelial monolayer (a negative control) and allowed to migrate for $24 \mathrm{hrs}$ to bottom wells. The living cells in bottom wells were counted by trypan blue exclusion assays under a light microscope.

\section{Cytokine treatment}

The indicated cells $\left(5 \times 10^{5} /\right.$ dish $)$ were plated overnight in $35 \mathrm{~mm}$ dishes in RPMI-1640 supplemented with $10 \%$ FBS. The cells were serum-deprived for $24 \mathrm{hrs}$ and then treated for $3 \mathrm{hrs}$ with the indicated cytokine for 3 hrs followed by total RNA isolation.

\section{HAS3 inhibition or neutralization}

The indicated cells were treated for 6-24 hrs with the neutralizing HAS3 antibody $(10 \mu \mathrm{g} / \mathrm{mL})$, control $\mathrm{IgG}(10 \mu \mathrm{g} /$ $\mathrm{mL}$ ), 4-MU (1 mM) or $0.1 \%$ DMSO (vehicle control) prior to cell-based assays or RNA isolation for RT-PCR analysis.

\section{Promoter-driven luciferase reporter assay}

Following seeding $10^{5}$ cells/well in triplicate in 24well plates for 16-18 hrs, cells were transfected by using Lipofectamine 2000 with the indicated promoter construct (400 ng) and pRL-TK (20 ng) as transfection efficiency control with or without $100 \mathrm{ng}$ HA-p65 (from Karin M at University of California, San Diego). Luciferase activities were measured using Dual-Luciferase Reporter Assays and normalized to Renilla luciferase activity at 48 hrs post-transfection.

\section{Chromatin immunoprecipitation and qPCR (ChIP-qPCR)}

ChIP was performed with EZ-ChIP kits (Millipore, Darmstadt, Germany). Briefly, oral cancer cells were serumdeprived for 24 hours and then treated for $3 \mathrm{hrs}$ with $50 \mathrm{ng} /$ $\mathrm{ml}$ of TNF- $\alpha$ for $3 \mathrm{hrs}$. We performed DNA cross-linking by adding $1 \%$ formaldehyde into cell cultures for $10 \mathrm{~min}$, followed by neutralization for $5 \mathrm{~min}$ with glycine at $0.125 \mathrm{M}$.
Cells were lysed with a lysis buffer with protease inhibitors and sonicated to shear genomic DNA to the lengths in 100$800 \mathrm{bp}$. The chromatin fragments were immunoprecipitated with isotypic control IgG or anti-NF- $\mathrm{kB}$ antibodies. We detected ChIP DNA by qPCR and the primers for NFkB sites (Table 1). Following normalizing ChIP samples with their corresponding input chromatin $(\Delta \mathrm{Ct})$, the enrichment was defined as change in $\mathrm{Ct}$ in treated versus untreated control samples $(\Delta \Delta \mathrm{Ct})$, relative to IgG control.

\section{Statistical analysis}

Statistical analyses were performed using a oneway analysis of variance (ANOVA) to compare all pairs of experimental groups. Data were represented as mean $\pm \mathrm{SD}$ or SEM. $p<0.05$ was regarded as statistically significant. For comparison of two groups, two-tailed student's t tests were used. All the statistical analyses were performed using Graphpad Prism software. We used linear regression and Pearson correlation to assess the relationship between HAS3 and TNF- $\alpha$ expression. We also used Pearson Chisquare to detect a relationship between clinicopathologic characteristics and HAS3 or TNF- $\alpha$ expression. The Kaplan-Meier method and log-rank test were used to compare the survival among high and low patient groups of HAS3 or TNF- $\alpha$.

\section{ACKNOWLEDGMENTS}

We thank Miss Chang MZ for her technical help in IHC staining, and Dr Hsu LC at National Taiwan University for the discussion on NF- $\kappa \mathrm{B}$ activation during manuscript preparation.

\section{CONFLICTS OF INTEREST}

All the authors in this manuscript state no conflicts of interest.

\section{GRANT SUPPORT}

This work was supported by Ministry of Science and Technology (MOST 102-2320-B-006-047; MOST 105-2314-B-006-073; MOST 105-2320-B-006-035) to $\mathrm{Wu} \mathrm{LW}$ and Tsai ST, and by Ministry of Health and Welfare (MOHW105-TDU-B-211-124-003) to Wang YC in Taiwan.

\section{REFERENCES}

1. Monslow J, Govindaraju P, Pure E. Hyaluronan - a functional and structural sweet spot in the tissue microenvironment. Front Immunol. 2015; 6:231.

2. Shigeishi H, Higashikawa K, Takechi M. Role of receptor for hyaluronan-mediated motility (RHAMM) in human 
head and neck cancers. J Cancer Res Clin Oncol. 2014; 140:1629-1640.

3. Franzmann EJ, Schroeder GL, Goodwin WJ, Weed DT, Fisher P, Lokeshwar VB. Expression of tumor markers hyaluronic acid and hyaluronidase (HYAL1) in head and neck tumors. Int J Cancer. 2003; 106:438-445.

4. Petrey AC, de la Motte CA. Hyaluronan, a crucial regulator of inflammation. Front Immunol. 2014; 5:101.

5. Kobayashi N, Miyoshi S, Mikami T, Koyama H, Kitazawa M, Takeoka M, Sano K, Amano J, Isogai Z, Niida S, Oguri K, Okayama M, McDonald JA, Kimata K, Taniguchi S, Itano N. Hyaluronan deficiency in tumor stroma impairs macrophage trafficking and tumor neovascularization. Cancer Res. 2010; 70:7073-7083.

6. Toole BP. Hyaluronan: from extracellular glue to pericellular cue. Nat Rev Cancer. 2004; 4:528-539.

7. Adamia S, Maxwell CA, Pilarski LM. Hyaluronan and hyaluronan synthases: potential therapeutic targets in cancer. Curr Drug Targets Cardiovasc Haematol Disord. 2005; 5:3-14.

8. Torronen K, Nikunen K, Karna R, Tammi M, Tammi R, Rilla K. Tissue distribution and subcellular localization of hyaluronan synthase isoenzymes. Histochem Cell Biol. 2014; 141:17-31.

9. Pure E, Assoian RK. Rheostatic signaling by CD44 and hyaluronan. Cell Signal. 2009; 21:651-655.

10. Kothapalli D, Zhao L, Hawthorne EA, Cheng Y, Lee E, Pure E, Assoian RK. Hyaluronan and CD44 antagonize mitogen-dependent cyclin D1 expression in mesenchymal cells. J Cell Biol. 2007; 176:535-544.

11. Liu N, Gao F, Han Z, Xu X, Underhill CB, Zhang L. Hyaluronan synthase 3 overexpression promotes the growth of TSU prostate cancer cells. Cancer Res. 2001; 61:5207-5214.

12. Bullard KM, Kim HR, Wheeler MA, Wilson CM, Neudauer CL, Simpson MA, McCarthy JB. Hyaluronan synthase-3 is upregulated in metastatic colon carcinoma cells and manipulation of expression alters matrix retention and cellular growth. Int J Cancer. 2003; 107:739-746.

13. Kultti A, Zhao C, Singha NC, Zimmerman S, Osgood RJ, Symons R, Jiang P, Li X, Thompson CB, Infante JR, Jacobetz MA, Tuveson DA, Frost GI, Shepard HM, Huang Z. Accumulation of extracellular hyaluronan by hyaluronan synthase 3 promotes tumor growth and modulates the pancreatic cancer microenvironment. Biomed Res Int. 2014; 2014:817613.

14. Twarock S, Freudenberger T, Poscher E, Dai G, Jannasch K, Dullin C, Alves F, Prenzel K, Knoefel WT, Stoecklein NH, Savani RC, Homey B, Fischer JW. Inhibition of oesophageal squamous cell carcinoma progression by in vivo targeting of hyaluronan synthesis. Mol Cancer. 2011; 10:30.

15. Chang IW, Liang PI, Li CC, Wu WJ, Huang CN, Lin VC, Hsu CT, He HL, Wu TF, Hung CH, Li CF. HAS3 underexpression as an indicator of poor prognosis in patients with urothelial carcinoma of the upper urinary tract and urinary bladder. Tumour Biol. 2015; 36:5441-5450.

16. Kohi S, Sato N, Cheng XB, Koga A, Higure A, Hirata $\mathrm{K}$. A novel epigenetic mechanism regulating hyaluronan production in pancreatic cancer cells. Clin Exp Metastasis. 2016; 33:225-230.

17. Knudson W, Biswas C, Li XQ, Nemec RE, Toole BP. The role and regulation of tumour-associated hyaluronan. Ciba Found Symp. 1989; 143:150-159; discussion 159-169, 281-155.

18. Kultti A, Li X, Jiang P, Thompson CB, Frost GI, Shepard HM. Therapeutic targeting of hyaluronan in the tumor stroma. Cancers (Basel). 2012; 4:873-903.

19. Xing RD, Chang SM, Li JH, Li H, Han ZX. Serum hyaluronan levels in oral cancer patients. Chin Med J (Engl). 2008; 121:327-330.

20. Kosunen A, Ropponen K, Kellokoski J, Pukkila M, Virtaniemi J, Valtonen H, Kumpulainen E, Johansson R, Tammi R, Tammi M, Nuutinen J, Kosma VM. Reduced expression of hyaluronan is a strong indicator of poor survival in oral squamous cell carcinoma. Oral Oncol. 2004; 40:257-263.

21. Tammi RH, Kultti A, Kosma VM, Pirinen R, Auvinen P, Tammi MI. Hyaluronan in human tumors: pathobiological and prognostic messages from cell-associated and stromal hyaluronan. Semin Cancer Biol. 2008; 18:288-295.

22. Sironen RK, Tammi M, Tammi R, Auvinen PK, Anttila M, Kosma VM. Hyaluronan in human malignancies. Exp Cell Res. 2011; 317:383-391.

23. Spicer AP, Olson JS, McDonald JA. Molecular cloning and characterization of a cDNA encoding the third putative mammalian hyaluronan synthase. J Biol Chem. 1997; 272:8957-8961.

24. Jacobson A, Brinck J, Briskin MJ, Spicer AP, Heldin P. Expression of human hyaluronan synthases in response to external stimuli. Biochem J. 2000; 348 Pt 1:29-35.

25. Bourguignon LY, Zhu H, Shao L, Chen YW. CD44 interaction with c-Src kinase promotes cortactin-mediated cytoskeleton function and hyaluronic acid-dependent ovarian tumor cell migration. J Biol Chem. 2001; 276:7327-7336.

26. Wang SJ, Bourguignon LY. Hyaluronan and the interaction between CD44 and epidermal growth factor receptor in oncogenic signaling and chemotherapy resistance in head and neck cancer. Arch Otolaryngol Head Neck Surg. 2006; 132:771-778.

27. Sato K. Cellular functions regulated by phosphorylation of EGFR on Tyr845. Int J Mol Sci. 2013; 14:10761-10790.

28. Deshmane SL, Kremlev S, Amini S, Sawaya BE. Monocyte chemoattractant protein-1 (MCP-1): an overview. J Interferon Cytokine Res. 2009; 29:313-326.

29. Beck-Schimmer B, Oertli B, Pasch T, Wuthrich RP. Hyaluronan induces monocyte chemoattractant protein-1 
expression in renal tubular epithelial cells. J Am Soc Nephrol. 1998; 9:2283-2290.

30. Chanmee T, Ontong P, Konno K, Itano N. Tumorassociated macrophages as major players in the tumor microenvironment. Cancers (Basel). 2014; 6:1670-1690.

31. Liu G, Xia XP, Gong SL, Zhao Y. The macrophage heterogeneity: difference between mouse peritoneal exudate and splenic F4/80+ macrophages. J Cell Physiol. 2006; 209:341-352.

32. Ijuin C, Ohno S, Tanimoto K, Honda K, Tanne K. Regulation of hyaluronan synthase gene expression in human periodontal ligament cells by tumour necrosis factoralpha, interleukin-1beta and interferon-gamma. Arch Oral Biol. 2001; 46:767-772.

33. Campo GM, Avenoso A, Campo S, Angela D, Ferlazzo AM, Calatroni A. TNF-alpha, IFN-gamma, and IL-1beta modulate hyaluronan synthase expression in human skin fibroblasts: synergistic effect by concomital treatment with FeSO4 plus ascorbate. Mol Cell Biochem. 2006; 292:169-178.

34. Karin M, Ben-Neriah Y. Phosphorylation meets ubiquitination: the control of NF-[kappa]B activity. Annu Rev Immunol. 2000; 18:621-663.

35. Wang S, Zhen L, Liu Z, Ai Q, Ji Y, Du G, Wang Y, Bu $\mathrm{Y}$. Identification and analysis of the promoter region of the human HAS3 gene. Biochem Biophys Res Commun. 2015; 460:1008-1014.

36. Lee SH, Hong HS, Liu ZX, Kim RH, Kang MK, Park NH, Shin KH. TNFalpha enhances cancer stem cell-like phenotype via Notch-Hes1 activation in oral squamous cell carcinoma cells. Biochem Biophys Res Commun. 2012; 424:58-64.

37. Triggs-Raine B, Natowicz MR. Biology of hyaluronan: Insights from genetic disorders of hyaluronan metabolism. World J Biol Chem. 2015; 6:110-120.

38. Krishnan R, Thayalan DK, Padmanaban R, Ramadas R, Annasamy RK, Anandan N. Association of serum and salivary tumor necrosis factor-alpha with histological grading in oral cancer and its role in differentiating premalignant and malignant oral disease. Asian Pac J Cancer Prev. 2014; 15:7141-7148.

39. Li P, Xiang T, Li H, Li Q, Yang B, Huang J, Zhang X, Shi Y, Tan J, Ren G. Hyaluronan synthase 2 overexpression is correlated with the tumorigenesis and metastasis of human breast cancer. Int J Clin Exp Pathol. 2015; 8:12101-12114.

40. Golshani R, Lopez L, Estrella V, Kramer M, Iida N, Lokeshwar VB. Hyaluronic acid synthase-1 expression regulates bladder cancer growth, invasion, and angiogenesis through CD44. Cancer Res. 2008; 68:483-491.

41. Brinck J, Heldin P. Expression of recombinant hyaluronan synthase (HAS) isoforms in $\mathrm{CHO}$ cells reduces cell migration and cell surface CD44. Exp Cell Res. 1999; 252:342-351.

42. Vigetti D, Karousou E, Viola M, Deleonibus S, De Luca G, Passi A. Hyaluronan: biosynthesis and signaling. Biochim Biophys Acta. 2014; 1840:2452-2459.

43. Chanmee T, Ontong P, Kimata K, Itano N. Key Roles of Hyaluronan and Its CD44 Receptor in the Stemness and Survival of Cancer Stem Cells. Front Oncol. 2015; 5:180.

44. Green TP, Fennell M, Whittaker R, Curwen J, Jacobs V, Allen J, Logie A, Hargreaves J, Hickinson DM, Wilkinson RW, Elvin P, Boyer B, Carragher N, Ple PA, Bermingham A, Holdgate GA, et al. Preclinical anticancer activity of the potent, oral Src inhibitor AZD0530. Mol Oncol. 2009; $3: 248-261$.

45. Rayahin JE, Buhrman JS, Zhang Y, Koh TJ, Gemeinhart RA. High and low molecular weight hyaluronic acid differentially influence macrophage activation. ACS Biomater Sci Eng. 2015; 1:481-493.

46. Campo GM, Avenoso A, Campo S, D'Ascola A, Nastasi G, Calatroni A. Small hyaluronan oligosaccharides induce inflammation by engaging both toll-like-4 and CD44 receptors in human chondrocytes. Biochem Pharmacol. 2010; 80:480-490.

47. Balkwill F. Tumour necrosis factor and cancer. Nat Rev Cancer. 2009; 9:361-371.

48. Wu Y, Zhou BP. TNF-alpha/NF-kappaB/Snail pathway in cancer cell migration and invasion. Br J Cancer. 2010; 102:639-644.

49. Hsu TC, Nair R, Tulsian P, Camalier CE, Hegamyer GA, Young MR, Colburn NH. Transformation nonresponsive cells owe their resistance to lack of p65/nuclear factorkappaB activation. Cancer Res. 2001; 61:4160-4168.

50. Chen YJ, Jin YT, Shieh DB, Tsai ST, Wu LW. Molecular characterization of angiogenic properties of human oral squamous cell carcinoma cells. Oral Oncol. 2002; 38:699-705.

51. Fang WY, Chen YW, Hsiao JR, Liu CS, Kuo YZ, Wang YC, Chang KC, Tsai ST, Chang MZ, Lin SH, Wu LW. Elevated S100A9 expression in tumor stroma functions as an early recurrence marker for early-stage oral cancer patients through increased tumor cell invasion, angiogenesis, macrophage recruitment and interleukin-6 production. Oncotarget. 2015; 6:28401-28424. doi: 10.18632/ oncotarget.4951.

52. Lin SC, Liu CJ, Chiu CP, Chang SM, Lu SY, Chen YJ. Establishment of OC3 oral carcinoma cell line and identification of NF-kappa B activation responses to areca nut extract. J Oral Pathol Med. 2004; 33:79-86.

53. Schmittgen TD, Livak KJ. Analyzing real-time PCR data by the comparative C(T) method. Nat Protoc. 2008; 3:1101-1108. 